\title{
Chronicle of Nanocelluloses (NCs) for Catalytic Applications: Key Advances
}

\author{
Loredana Maiuolo, Vincenzo Algieri *(1), Fabrizio Olivito*(D), Matteo Antonio Tallarida *(D), Paola Costanzo (1), \\ Antonio Jiritano and Antonio De Nino *(D)
}

\author{
Dipartimento di Chimica e Tecnologie Chimiche, Università della Calabria, 87036 Rende, Italy; \\ maiuolo@unical.it (L.M.); paola.costanzo@unical.it (P.C.); antonio.j@hotmail.it (A.J.) \\ * Correspondence: vincenzo.algieri@unical.it (V.A.); fabrizio.olivito@unical.it (F.O.); \\ matteoa.tallarida@unical.it (M.A.T.); denino@unical.it (A.D.N.)
}

Citation: Maiuolo, L.; Algieri, V.; Olivito, F.; Tallarida, M.A.; Costanzo, P.; Jiritano, A.; De Nino, A. Chronicle of Nanocelluloses (NCs) for Catalytic Applications: Key Advances. Catalysts 2021, 11, 96. https:// doi.org/10.3390/catal11010096

Received: 18 December 2020 Accepted: 8 January 2021 Published: 12 January 2021

Publisher's Note: MDPI stays neutral with regard to jurisdictional clai$\mathrm{ms}$ in published maps and institutional affiliations.

Copyright: $(\odot 2021$ by the authors. Licensee MDPI, Basel, Switzerland. This article is an open access article distributed under the terms and conditions of the Creative Commons Attribution (CC BY) license (https:// creativecommons.org/licenses/by/ $4.0 /)$.
Abstract: Nanocellulose (NC) is a biomaterial with growing interest in the field of nanocomposites and sustainable materials. NC has various applications including biodegradable materials, reinforcing agents, packaging films, transpiring membranes and medical devices. Among the many applications, the use of NC functionalized with organic and inorganic groups has found wide use as a catalyst in chemical transformations. The goal of this review is to collect the current knowledge on its catalytic applications for chemical groups conversion. We have chosen to organize the manuscript according to subdivision of NC into Bacterial Nanocellulose (BNC), Cellulose Nanocrystals (CNCs), and Cellulose Nanofibers (CNFs) and their role as inorganic- and organic-functionalized NC-catalysts in organic synthesis. However, in consideration of the fact that the literature on this field is very extensive, we have decided to focus our attention on the scientific productions of the last five years.

Keywords: bacterial nanocellulose (BNC); cellulose nanocrystals (CNC); cellulose nanofibrils (CNFS); nanocellulose functionalization; nanocellulose synthesis; catalytic nanocellulose applications

\section{Introduction}

Cellulose is the main component of lignocellulosic biomasses, with an average percentage of 40-50 of the total weight. It is the most abundant polysaccharide on Earth, with an estimated annual production of $7.5 \times 10^{10}$ tons [1,2]. From a chemical point of view, it is composed of $\beta$-D-glucopyranoses (ca. 5000 and 10,000 units), linked by $\beta$-1,4-glycosidic bonds. $\beta$-Glycosidic bonds force the entire structure of the polysaccharide to a linear arrangement, due to the pyranose chair conformation and the equatorial disposition of the substituents within the subunits, that corresponds to a minimum of energy of the entire structure [3].

Due to the extensive potential applications of this inexhaustible material [4,5], nanocelluloses (NCs) became in brief time one of the main topics of research worldwide. In particular, NCs have shown excellent properties like strength, high Young's modulus, biocompatibility, tunable self-assembly, and thixotropic behavior, becoming groundbreaking in plenty of fields like optoelectronics, antibacterial coatings, packaging, engineered polymer composites, medicine (tissue scaffolds, drug delivery, biosensors, etc.), energy storage, catalysis, and environmental remediation [6,7]. Very often the nanocellulose (NC) is subjected to functional modifications through chemical reactions. These modifications are frequently performed to improve the characteristics and performance of nanocellulosebased materials and more specifically to obtain nanocellulose derivatives with enhanced lipophilic characteristics through acetylation, benzoylation or alkylation and with increased hydrophilic features by sulfonation or oxidation reactions. At the same time, it is necessary to preserve the structural integrity of modified nanocellulose to ensure its stability during the use as heterogeneous catalyst in organic transformations. Moreover, the almost always 
superficial modifications ensure the excellent catalytic performance and the maintenance of its intimate structure for an easy recovery and a possible reuse of the catalyst.

Despite the always growing number of studies about the preparation and their applicative evaluation, $\mathrm{NC}$ materials can be classified into just three main nanoforms: bacterial nanocellulose (BNC), cellulose nanocrystals (CNCs), and cellulose nanofibers (CNFs). The parameters which define the classification of these materials are mainly related to the methods of preparation (biological, chemical, and mechanical), the morphological attributes, and the crystallinity degree of the material; for a deeper point of view on the physical properties of NCs, the reader can refer to [8].

In spite of a lot of works have been published about the preparation, the chemical transformation and the general employ of this nanomaterials, to our knowledge literature reports only two papers which examine the role of nanoparticles (NPs)-decorated NCderivatives as inorganic catalysts $[9,10]$. On the other hand, the catalytic application of organic-functionalized NCs still have not been properly reviewed. For these reasons, the goal of this work is to provide a complete review on the role of inorganic- and organicfunctionalized NC-derivatives in organic synthesis with a particular emphasis on the last five years.

\section{Bacterial Nanocellulose}

Bacterial nanocellulose (BNC), also defined bacterial cellulose (BC), is an exceptional natural polymer with a great variety of technical applications. BNC was firstly described in a scientific paper by A.J. Brown in 1886, as produced by Bacterium aceti through fermentative processes to produce nanoscale cellulose [11]. Cellulose nanofibers can be also produced, as extracellular secretion, by several species of bacteria, such as Aerobacter, Acetobacter, Agrobacterium, Azotobacter, Rhizobium, and Pseudomonas [12,13]. Acetobacter xylinus, also known as Gluconacetobacter or Komagataeibacter xylinus, a non-pathogenic Gram-negative aerobic bacteria, is considered the most efficient cellulose producer, and the most extensively studied [12]. BNC has the same molecular formula as plant cellulose but is characterized by a 3D porous network structure with unique features. First of all, it has high purity since it is hemicellulose- and lignin-free, with a high water content of $99 \%$ and hydrophilicity [13]. It possesses high crystallinity (up to 80\%) with a resulting high thermal stability and a high degree of polymerization (up to 20,000). Finally, BNC exhibits high flexibility, with a value of $118 \mathrm{GPa}$ for Young's modulus of single nanofiber, which is comparable to steel [14]. BNC nanofibers have a high aspect ratio around 20-100 nm in width and 1-9 $\mu \mathrm{m}$ length, with a surface area superior to that of plant cellulose [12]. BNC is very versatile since it can be obtained in different shapes and thicknesses, such as pellicle, disk, or aggregate. Finally, BNC is more environmentally friendly than its vegetal counterpart, due to its high purity, which does not require additional purification procedures. Moreover, the identification of different waste biomass as a useful carbon source for a prospective industrial BNC production, together with its considerable environmental biodegradability and biocompatibility make it an ecofriendly material. The BNC features are influenced by the fermentation conditions such as the carbon and nitrogen sources, the temperature, the incubation time, and agitation. Furthermore, it is possible to alter the BNC structure and the morphology by adding chemical reagents in the culture medium or the growing fibers, to give nanocomposite properties $[15,16]$. In this way it is possible to obtain a versatile template material for various applications, from medical devices to innovative materials with electrical properties $[16,17]$.

Thanks to its numerous hydroxyl groups it could be chemically functionalized to give materials with enhanced chemical and physical properties. As an example, BNC oxidation enhances its biodegradability and solubility. Instead, esterification of the BNC could be a strategy for improving the capability of integration with other organic polymers, or for the delivery of active pharmaceutical ingredients [12].

Very attractive aerogels can be obtained from BNC, through freeze-drying processes. The resulting porous solid material can be used as a template for numerous catalysts in 
diverse applications $[12,18,19]$. It is worth noting that these BNC aerogels also are the starting material in high-temperature pyrolysis processes under an inert atmosphere, to obtain carbon nanofibers with a 3D nanostructure [20]. Although numerous papers reported the use of these advantageous catalysts, this topic is out of scope for the present review, and only pristine BNC, suitably modified without pyrolysis processes will be examined.

Readers can find a complete survey about the advancements in bacterial cellulose applications in previous, very exhaustive reviews [9,21-26]. The most interesting bacterial cellulose applications as a catalyst from 2016 until the present, are reported herein.

\subsection{Inorganic Functionalization of Bacterial Nanocellulose and Catalytic Applications}

Many inorganic compounds, like metal oxides, metal sulfides, silica, or metal nanoparticles, have been integrated into BNC, exploiting its isotropic 3D nanostructure to obtain versatile heterogeneous catalysts. With the aim to prepare nanocomposites with enhanced activity, it is possible to add these inorganic materials through different synthetic strategies. Among them, three strategies have been most used and reported in the literature: (i) the mixing under simple agitation or ultrasound-assisted conditions; (ii) the absorption through solvothermal processes; and (iii) in situ incorporation in the growth medium. The catalytic applications of these new materials are classified in the following sections.

\subsubsection{Catalytic Transformation of Organic Compounds for Environmental Purposes}

Many efforts have been made in the last years for the treatment of industrial wastewater, to eliminate or limit the pollutants. For example, the textile industries contribute a lot to aquatic pollution with azoic dyes. The reduction of these contaminants in non- or less-toxic compounds was investigated, using transition metal-based nanoparticles, which are more economical than noble metal nanoparticles. Thiruvengadam and Vitta in 2017, proposed the use of BNC as flexible and multifunctional Ni-based nanocomposite to reduce methyl orange (MO) used as a model dye pollutant [27]. The authors obtained Nickel-Bacterial Cellulose (NiBNC) nanocomposite at different nickel concentration using the "inverse chemical reduction" technique. It consisted of the immersion of a BNC hydrogel firstly in a sodium borohydride $\left(\mathrm{NaBH}_{4}\right)$ solution and subsequently in a $\mathrm{NiCl}_{2}$ solution. Finally, the resulting black colored NiBNC was hot-pressed at $70{ }^{\circ} \mathrm{C}$ and $4 \mathrm{MPa}$, to obtain a dried NiBNC sheet with a final formation of highly interconnected metal nanoparticles in a BNC network, with magnetic and electrical properties. The reduction catalytic activity was also tested, and the NiBNC was able to reduce the UV-absorption of a methyl orange solution if compared with pristine BNC. The reusability of this catalyst was checked, and the authors highlighted that a high efficiency was maintained if the catalyst was not stored in an aqueous solution between the cycles. Xu et al., in 2018, developed a novel flexible membrane for the water pollution treatment, based on BNC loaded with graphene oxide (GO) and palladium nanoparticles (Pd-NPs) [28]. At first, GO flakes were introduced as a uniform dispersion in the growing BNC nanofibers, allowing intercalation in a "layer by layer" manner. The resulting material showed more robustness of the pristine BNC, a crucial property for water treatment materials. After the formation and cleaning in alkaline solution, the GO/BNC hydrogel was cut in the desired measures and freeze-dried to give GO/BNC aerogel with a large specific surface area. To add Pd-NPs to the GO/BNC structure, it was immersed in a $\mathrm{PdCl}_{2}$ solution, dried, and then washed with a $\mathrm{NaBH}_{4}$ solution leading to in situ formations of Pd-NPs (Figure 1). The newly formed Pd/GO/BNC membrane showed a large loading of Pd-NPs in the final membrane and was used dried for the catalytic test, in which methyl orange dye-contaminated water, in presence of $\mathrm{NaBH}_{4}$, was filtered through it. The rate of methyl orange degradation was measured with a simple $\mathrm{Pd} / \mathrm{BNC}$ membrane that was lower compared to that of $\mathrm{Pd} / \mathrm{GO} / \mathrm{BNC}$ membrane. Its powerful activity was highlighted testing this sheet as a filter for a cocktail solution of contaminants with a concentration of $10 \mathrm{mg} \mathrm{L}^{-1}$ : methylene blue 1 (MB), 4-nitrophenol 2 (4-NP), and rhodamine 6G 3 (R6G). In all cases, the colored solution became completely colorless after filtration through the $\mathrm{Pd} / \mathrm{GO} / \mathrm{BNC}$ membrane, probably due to the lamellar 
structure of the membrane that assures an excellent interaction with the Pd-NPs for the reduction activity. It is worth noting that the entire membrane preparation procedure is easily scalable. This feature together with the high spread catalytic activity and the stability showed in the stress test, make this new material interesting for industrial application.

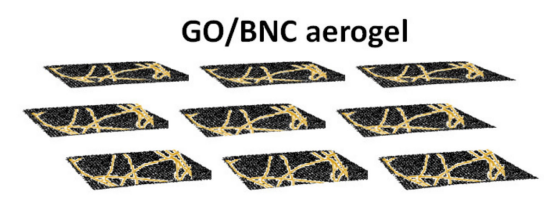

Graphene oxide
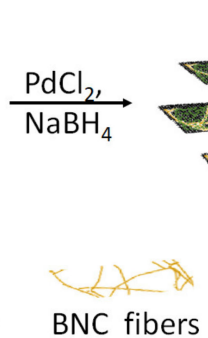

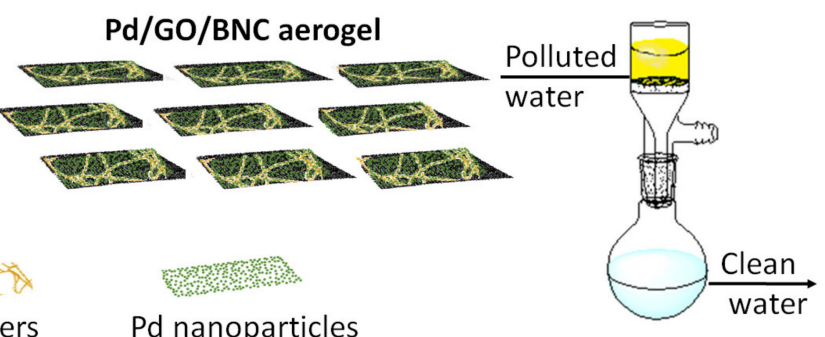

Pd nanoparticles

Figure 1. Schematic illustration of the steps involved in the fabrication of Pd/graphene oxide (GO)/bacterial nanocellulose (BNC) and its use.

Very recently, the research group of Kamal et al. proposed different examples in which BNC was used as a high surface area support for transition metal nanoparticles stabilized with carboxymethyl cellulose (CMC) like cobalt (CMC-Co-BNC) [29], copper (CMC-Cu-BNC) [30], and nickel (CMC-Ni-BNC) [31]. In these works, metal chloride and CMC $(1 \mathrm{wt} \%)$ solutions were mixed, then hydrazine hydrate and ascorbic acid were slowly added. Microwave heating of the resulting solution led to the carboxymethyl cellulosemetal (CMC-M) nanoparticles. Finally, the CMC-M-BNC dip-catalyst was obtained by simple dropping and spread of the CMC-M suspension on the BNC sheets previously obtained by a Gluconacetobacter xylinum culture (Scheme 1).
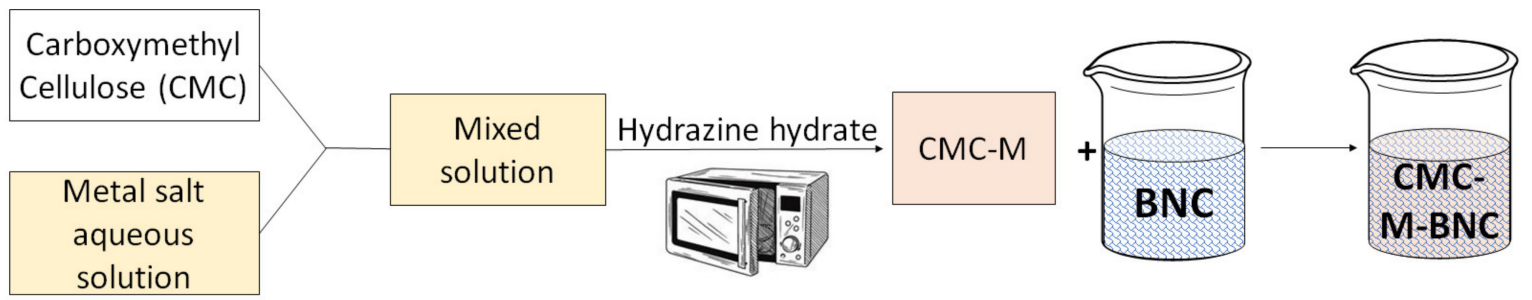

Scheme 1. Preparation of the colloidal carboxymethyl cellulose (CMC)-M nanoparticles and carboxymethyl cellulose (CMC)-M-BNC dip-catalyst.

All these catalysts were tested on the reduction of methylene blue $\mathbf{1}(\mathrm{MB})$ and different nitrophenols: 4-nitrophenol 2 (2-NP), 2,6-dinitrophenol 4 (2,6-DNP), and 2-nitrophenol 5 (2-NP) with CMC-Co-BNC, CMC-Cu-BNC, and CMC-Ni-BNC, respectively. In all cases, the CMC-M-BNC catalyst was able to reduce the dye pollutants, both alone and in combination, even if the colloidal CMC-M was found to catalyze the reaction faster than the heterogeneous CMC-M-BNC. The reusability was also tested with good conversion results after four cycles. The easier separation procedure of the heterogeneous catalyst, compared to the colloidal one that requires long centrifugation times for its recovery, suggests that the supported CMC-M-BNC could be more useful for real applications.

The hypothesized reaction mechanism could explain the different reaction rates measured for the CMC-M and the CMC-M-BNC. Both the reducible molecules and the sodium borohydride move on the nanoparticle surface. The $\mathrm{NaBH}_{4}$ transfers a hydride on the reducible molecule, while an electron was transferred from it to the catalyst. Then, the reduced molecules leave the catalyst surface and spread in the solution. By then, another reducible molecule could be adsorbed. The authors hypothesized that the anionic surface of the CMC favored a strong interaction with the reducible molecules. Consequently, a fast catalytic reaction occurs (Scheme 2). 

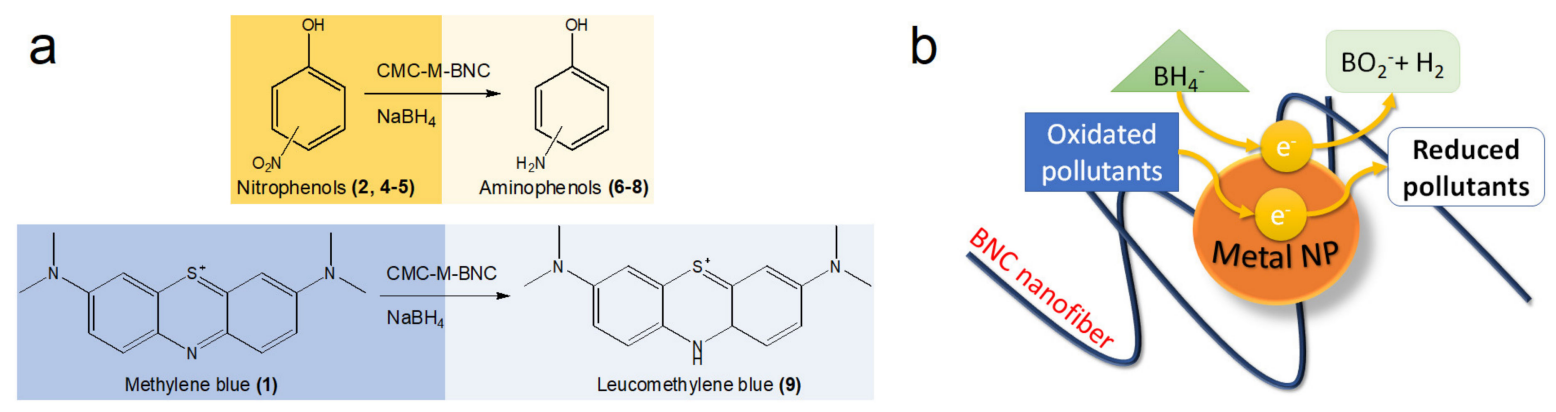

Scheme 2. (a) Chemical reduction of nitrophenols $(2,4,5)$ and methylene blue (1) by $\mathrm{NaBH}_{4}$ using CMC-M or CMC-M-BNC; (b) reaction mechanism.

After simple oxidation of the pristine BNC, it is possible to highly improve the metal absorption capacity maintaining, at the same time the crystallinity and crystal size of the nanofibers [15]. In addition, BNC TEMPO-mediated oxidation has been combined, also with defibrillation to allow a higher metal nanoparticles inclusion capability. In 2017, Chen et al. exploited this option using the 2,2,6,6-tetramethylpiperidine-1-oxyradical (TEMPO)mediated oxidation reaction to obtain a $\mathrm{BNC}$ with carboxyl groups on the glucose moieties (TOBNC) as support for Au nanoparticles (Au-TOBNC) [32]. Before the oxidation reaction, it was necessary to fibrillate BNC into a slurry, then the reaction proceeded by adding TEMPO, $\mathrm{NaBr}$, and $\mathrm{NaClO}$ under mild aqueous conditions. The TOBNC as obtained was then mixed with a $\mathrm{HAuCl}_{4}$ solution in presence of sodium borohydride to give the Au-TOBNC catalyst (Scheme 3).
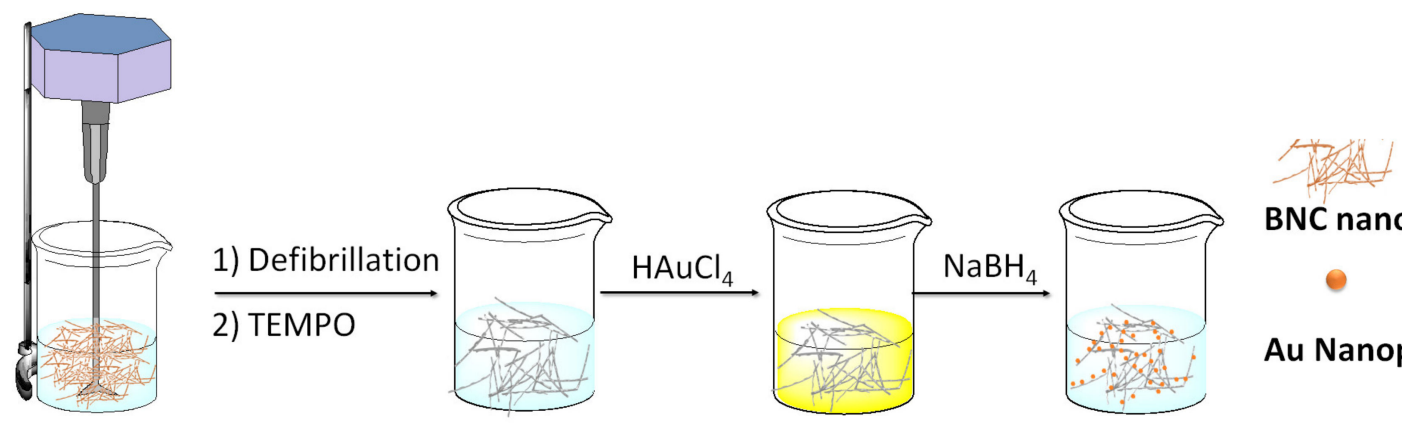

\section{BNC nanofiber}

○

Au Nanoparticles

Scheme 3. Synthetic procedure of AuNPs supported by TOBNCs.

The average particle size for AuNP-TOBNC was lower than the unsupported AuNPs, and it was probably due to the carboxyl groups, which in the dissociate form could immobilize tighter the AuNP, allowing a more uniform distribution of the particle size. The influence of the $\mathrm{pH}$ on the amount of AuNPs loaded was studied. When pH was 3.2-11.3 it was observed a changing color of the suspension reflecting the increase of the amount of AuNPs. It was probably due to the associate or dissociated form of the carboxyl groups. Then, the Au-TOBNC catalyst was tested for the reduction of 4-nitrophenol (4-NP) 2 by $\mathrm{NaBH}_{4}$ as a reaction model. The reduction of 4-nitrophenol (4-NP) 2 to 4-aminophenol 6 (4-AP) proceed almost 20-fold faster than the AuNP without TOBNC support. Probably, because the TOBNC allowed a better Au exposure to the reagent when adsorbed on the single nanofiber, it was well dispersed. Finally, the influence of the temperature on the reduction reaction was evaluated, and the rate of substrate activation and the rate of product desorption achieved a balance almost at $65^{\circ} \mathrm{C}$. This work was very important because of the higher catalytic efficiency than the values reported before for analog catalyst [33]. 


\subsubsection{Photocatalytic Applications of BNC-Inorganic Composites for} Environmental Remediation

The advanced oxidation processes (AOPs) are another way for the water removal of dyes and pollutants, which were under investigation through heterogeneous catalysis in the last year. Thanks to its unique features, the BNC can be considered an excellent material substrate for the design of a potential Fenton-type catalyst. In 2018, Wibowo et al. synthesized a Fenton-BNC catalyst, by immersing a BNC hydrogel in $\mathrm{FeCl}_{2}$ and $\mathrm{FeCl}_{3}$ solutions at different concentrations, with a 1:2 molar ratio between $\mathrm{Fe}(\mathrm{II})$ and $\mathrm{Fe}(\mathrm{III})$ [34]. After one night, the hydrogel color changed from white to yellow and was immersed in a $\mathrm{NaOH}(4 \mathrm{M})$ solution to oxidize the metal, with a final black color for the hydrogel. Finally, the Fenton-BNC hydrogel was freeze-dried to give a Fenton-BNC aerogel that was used for the catalytic degradation studies of methylene blue (MB) 1 , used as dye pollutant model. The authors demonstrated that the heterogeneous Fenton catalyst supported by BNC possessed better catalytic activity than the bare Fenton catalyst prepared without BNC. As a further advantage, Fenton-BNC could be easily recovered by using an external magnetic field thanks to its magnetic features.

Very recently, $\mathrm{Hu}$ and co-workers proposed a new efficient and recyclable photocatalyst based on $\mathrm{TiO}_{2}$, non-woven polypropylene (NWP), and $\mathrm{BNC}$ [35]. In particular, $\mathrm{TiO}_{2}$ nanoparticles were loaded onto NWP, and this sample was placed in the culture medium of Gluconacetobacter $x$., in order to fix the nanoparticles in the growing cellulose (Figure 2). The $\mathrm{TiO}_{2}-\mathrm{NWPBNC}$ was used for the $\mathrm{MB}$ degradation catalytic tests, confirming that $\mathrm{TiO}_{2}$ was efficiently embedded into the composite film, maintaining a good degradation performance with an MB removal rate over $92 \%$ after $2 \mathrm{~h}$ of reaction. Furthermore, after 5 cycles less than $10 \%$ of removal rate reduction was measured, showing also good reusability.

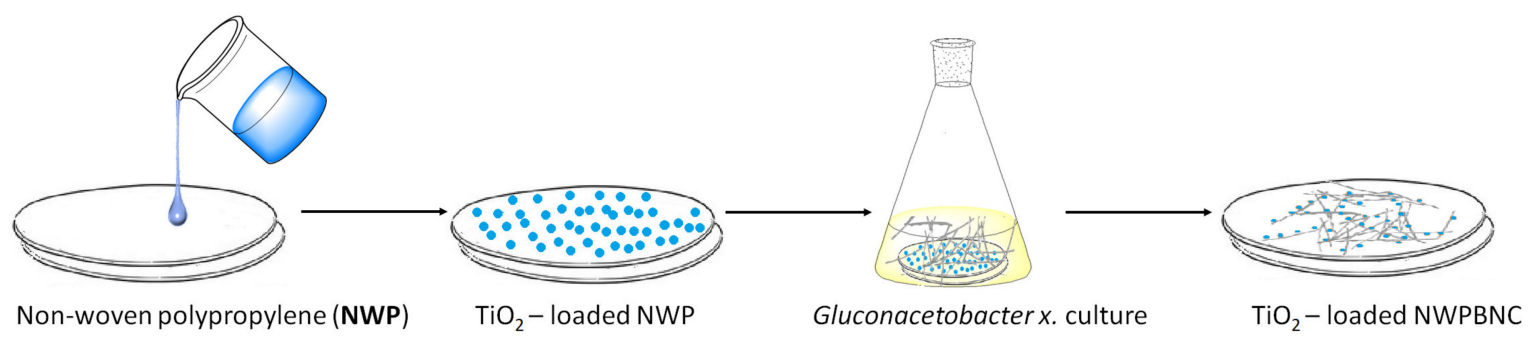

Figure 2. Preparation process of $\mathrm{TiO}_{2}$-loaded NWPBNC composite film.

2.1.3. Electro-Catalytic Applications of Inorganic-Functionalized Bacterial Nanocellulose

As previously reported [9], BNC can be converted into a material with electrical properties by inorganic functionalization with suitable transition metals. In this work, the authors measured an increase of the room temperature electrical conductance for a flexible BNC sheet functionalized with a $20 \mathrm{vol} \%$ of Ni nanoparticles. It is worth noting that the NiBNC membrane could be useful both for biodegradable and bendable electronic devices thanks to its unique properties to conduct both in the hydrogel or dried state, respectively.

Zhou and co-workers in 2019, developed a $\mathrm{CuO} / \mathrm{Cu}$ nanocomposite electrode supported on $\mathrm{BNC}$ as a catalyst for efficient $\mathrm{CO}_{2}$ electrochemical reduction to $\mathrm{CO}$ [36]. This electrode was obtained by applying an in situ chemical reduction process, in which BNC sheets were immersed in a $\mathrm{Cu}$ (II) salt solution of ethanol and water. $\mathrm{NaBH}_{4}$ was added as a reducing agent, together with an $\mathrm{NaOH}$ solution $(0.1 \mathrm{M})$, and the mixture was heated at $30{ }^{\circ} \mathrm{C}$ for $90 \mathrm{~min}$. Different $\mathrm{CuO} / \mathrm{Cu}$-BNC membranes were obtained as a function of the $\mathrm{NaBH}_{4}$ concentration after washing with deionized water. Electrochemical activity and performance tests were carried out and in particular, the $\mathrm{CuO} / \mathrm{Cu}_{4: 3}-\mathrm{BNC}$ prepared with a $0.3 \mathrm{M}$ concentration in $\mathrm{NaBH}_{4}$ (with a $4: 3$ molar ratio between $\mathrm{CuSO}_{4} \cdot 5 \mathrm{H}_{2} \mathrm{O}$ and $\mathrm{NaBH}_{4}$ ) was evaluated as an efficient catalyst for electrochemical $\mathrm{CO}_{2}$ reduction. The $\mathrm{CuO} / \mathrm{Cu}_{4: 3}-\mathrm{BNC}$ catalyst showed high faradaic efficiency of $53 \%$ for $\mathrm{CO}$ formation at a low overpotential of $490 \mathrm{mV}$, for over $40 \mathrm{~h}$. Furthermore, it was compared with a conventional 
$\mathrm{CuO} / \mathrm{Cu}$ composite catalyst supported on carbon paper and it was highlighted that an enhanced electro-catalytic performance was obtained due to its unique structural advantages, such as high surface area, optimal $\mathrm{CuO} / \mathrm{Cu}$ composition that allowed a facilitating charge, and mass transport and ability to promote the conversion of $\mathrm{CO}_{2}$.

\subsubsection{Synthetic Applications of BNCs Grafted with Inorganic Catalysts}

The use of a heterogeneous catalyst is in great demand, also in organic synthesis, and BNC responds with its peculiar features. In 2019, Jeremic et al. carried out an extensive study on the influence of the BNC production parameters and its use in transition metal nanocomposites for the catalysis of cross-coupling reactions [37]. Firstly, the authors studied the influence of the single parameters, such as $\mathrm{pH}$, glucose concentration, and day of incubation, for the optimization of BNC production. In addition, for the first time, they successfully used a sugar mixture, a product of grass biomass treatment [38], as a carbon source for BNC production, obtaining the valorization of non-food renewable biomass as starting material. Then, the authors evaluated BNC application as solid supports for transition metals for the synthesis of heterogeneous catalysts. They loaded onto BNC, Pd(II) or $\mathrm{Cu}$ (II) salts in a sodium borohydride solution in water at 140 and $70{ }^{\circ} \mathrm{C}$, respectively. Differences were observed in the metal catalyst's distribution, showing that $\mathrm{Cu}$ formed a spherical structure on the surface, while Pd nanoparticles were incorporated inside the BNC network. Furthermore, quadrupole inductively coupled plasma mass spectrometry (ICP-QMS) analysis showed that the amount of $\mathrm{Cu}$ on $\mathrm{Cu} / \mathrm{BNC}$ was 10-fold lower than Pd on $\mathrm{Pd} / \mathrm{BNC}$, indicating more efficient incorporation for the Pd catalyst than the Cu catalyst. For this reason, the Pd/BNC catalyst was chosen for the catalytic tests. The results of the Suzuki-Miyaura reaction performed with the Pd/BNC catalyst are reported in Table 1.

As expected, the coupling reaction gave higher yields using bromobenzene 9a with different arylboronic acids $\mathbf{1 0 a - 1 0 c}$, using water as an ecofriendly solvent, and highlighting the greenness of the whole process. Subsequently, the same recovered catalyst was used to catalyze the reduction of the nitro- to amino group of $\mathbf{1 1}$ and $\mathbf{1 1 d}$ with $\mathrm{H}_{2}$, with $99 \%$ yield for both compounds (Scheme 4).

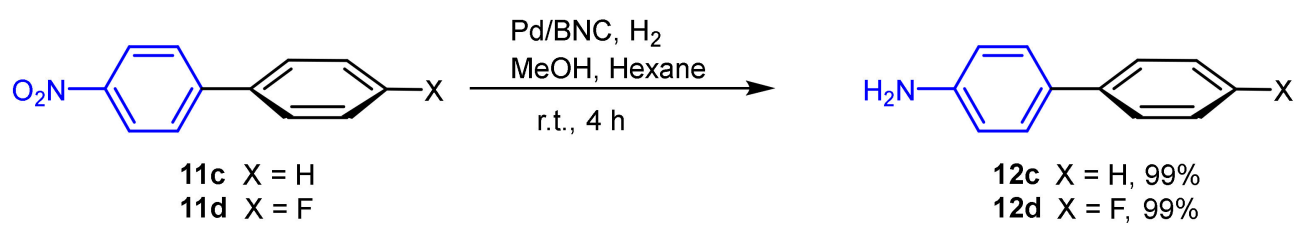

Scheme 4. Reduction of nitro-group catalyzed by Pd/BNC.

Finally, $\mathrm{Cu} / \mathrm{BNC}$ catalyst was also tested for the Chan-Lam coupling reaction between benzylamine 12 and phenylboronic acid 10a (Scheme 5). The authors supposed that the moderate observed yield was due to the low $\mathrm{Cu}$ incorporation on BNC. Anyway, the easy recovery and reusability, together with the negligible leaching of the metals confirmed these materials as good heterogeneous catalysts.<smiles>NCc1ccccc1</smiles>

12<smiles></smiles>

$10 a$<smiles>c1ccc(CNc2ccccc2)cc1</smiles>

$13,48 \%$

Scheme 5. Chan-Lam coupling reaction catalyzed by $\mathrm{Cu} / \mathrm{BNC}$. 
Table 1. Pd/BNC catalyzed Suzuki-Miyaura reaction of aryl halogenides with arylboronic acid in water.

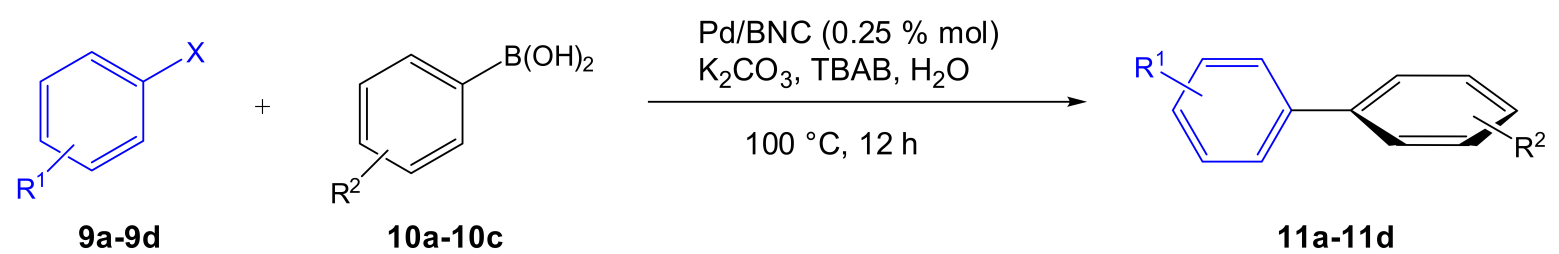

\begin{tabular}{|c|c|c|c|c|c|c|}
\hline Entry & Aryl Halide & Aryl Boronic Acid & Product & Yield (\%) & TON $^{a}$ & TOF $^{b}$ \\
\hline 1 & & & & 14 & 56 & 4.5 \\
\hline 2 & & & & 78 & 312 & 26 \\
\hline 3 & & & & 87 & 352 & 29 \\
\hline 4 & & & & 77 & 308 & 26 \\
\hline 5 & & $(\mathrm{OH})_{2}$ & & 86 & 344 & 28.6 \\
\hline 6 & $9 d$ & 10a & 11c & $23^{c}$ & 92 & 7.6 \\
\hline 7 & & $10 c$ & $11 d$ & 91 & 372 & 31 \\
\hline
\end{tabular}

a TON: Turnover number; ${ }^{\mathrm{b}} \mathrm{TOF}$ : Turnover frequency; ${ }^{\mathrm{c}}$ : In the presence of $\mathrm{Hg}$ excess (Pd: $\left.\mathrm{Hg}=1: 300\right)$.

\subsection{Surface Chemical Functionalization of Bacterial Nanocellulose and Catalytic Applications}

The introduction of sulfuric acid as functional group on the BNC surface can modify the surface polarity leading to a heterogeneous acid catalyst, with a high crystallinity and surface area. In 2018, Nikoofar and co-workers exploited this chemical modification to catalyze a multicomponent reaction in order to obtain pyrimidine fused heterocycles [39]. Multicomponent reactions (MCR) are very interesting and green tools to obtain useful scaffolds for medicinal chemistry [40]. Many green protocols have been developed in the last years [41,42], and the use of an heterogeneous catalyst can accelerate the reaction times and increases the reaction yields [43]. In this work, biodegradable and stable heterogeneous catalysts were tested in a four MCR (4-MCR). BNC sulfuric acid (s-BNC) together with nanofibrillated cellulose sulfuric acid (s-NFC) were obtained by the authors in mild condition by adding chlorosulfonic acid in n-hexane at $0{ }^{\circ} \mathrm{C}$ for $20 \mathrm{~min}$. The mixture was stirred at room temperature to remove the $\mathrm{HCl}$. Then, the catalysts were washed and dried to give s-BNC and s-NFC ready for the MCR reaction to give dihydropyrimido [4,5-b]quinolinetriones (Scheme 6). 


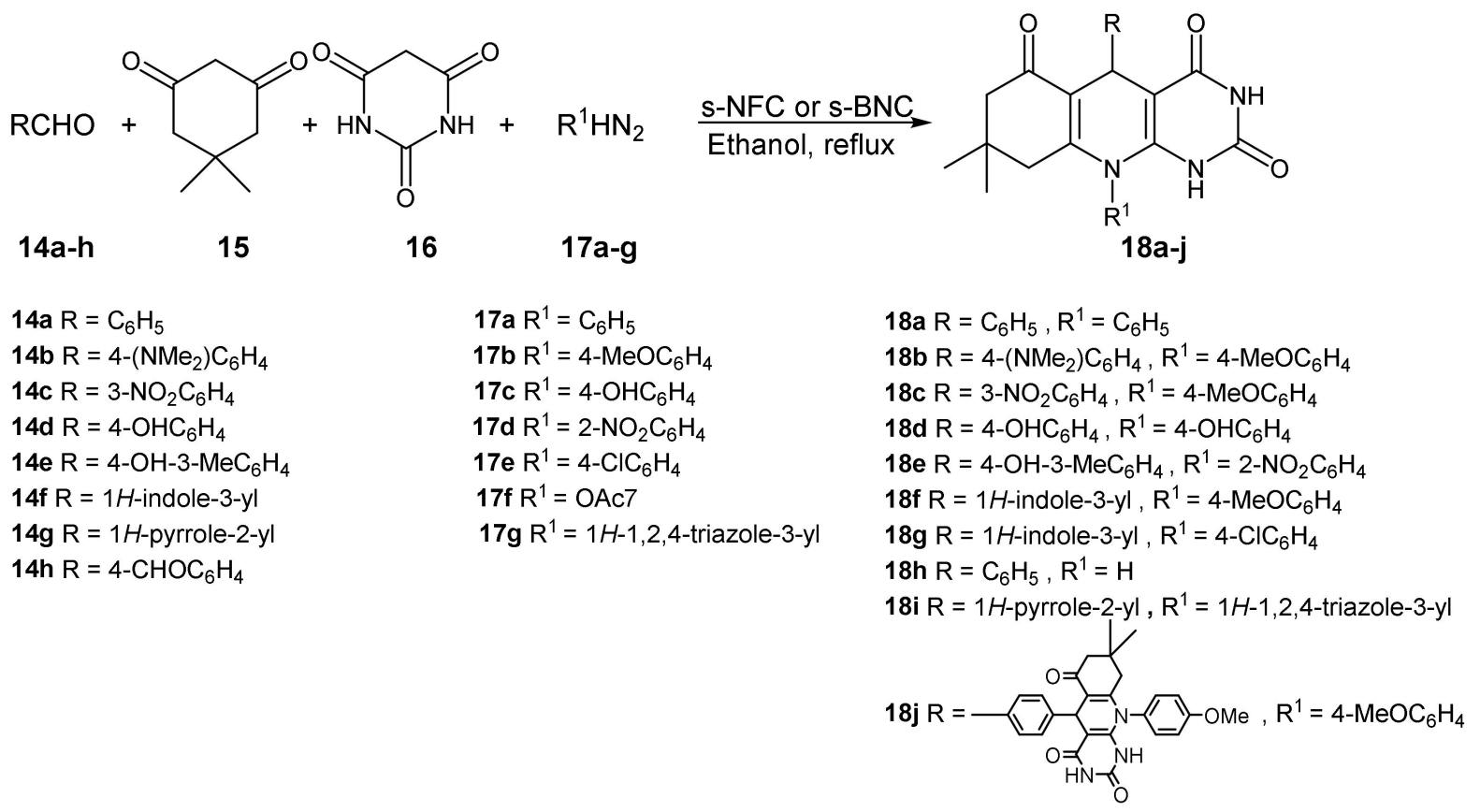

Scheme 6. Multicomponent reaction catalyzed by s-BNC and s-NFC.

The reaction conditions were tested using s-NFC, which showed good results both in water and ethanol. The optimized reaction conditions were applied for both the catalysts, and the results are reported in Table 2.

Table 2. Multicomponent reactions (MCR) for the synthesis of dihydropyrimido[4,5-b]quinolinetriones $\mathbf{1 8 a - 1 8 j}$ catalyzed by s-NFC or s-BNC in refluxing ethanol.

\begin{tabular}{|c|c|c|c|c|c|c|c|}
\hline \multirow{2}{*}{ Entry } & \multirow{2}{*}{ Aldehyde } & \multirow{2}{*}{ Amine } & \multirow{2}{*}{ Product } & \multicolumn{2}{|c|}{ s-NFC } & \multicolumn{2}{|c|}{ s-BNC } \\
\hline & & & & Time (Min) & Yield (\%) & Time (Min) & Yield (\%) \\
\hline 1 & $14 a$ & $15 a$ & $18 a$ & 45 & $92,90,90^{\mathrm{a}}$ & 40 & 94 \\
\hline 2 & $14 b$ & $15 b$ & $18 b$ & 90 & 90 & 70 & 91 \\
\hline 3 & $14 c$ & $15 b$ & $18 c$ & 60 & 85 & 50 & 83 \\
\hline 4 & $14 d$ & $15 c$ & $18 d$ & 105 & 95 & 90 & 94 \\
\hline 5 & $14 \mathrm{e}$ & $15 d$ & $18 \mathrm{e}$ & 90 & 93 & 80 & 90 \\
\hline 6 & $14 \mathrm{f}$ & $15 b$ & $18 f$ & 165 & 93 & 150 & 91 \\
\hline 7 & $14 \mathrm{f}$ & $15 e$ & $18 \mathrm{~g}$ & 105 & 95 & 95 & 90 \\
\hline 8 & $14 a$ & $15 f$ & $18 \mathrm{~h}$ & 75 & 90 & 60 & 88 \\
\hline 9 & $14 \mathrm{~g}$ & $15 g$ & $18 \mathrm{i}$ & 75 & 90 & 65 & 88 \\
\hline $10^{b}$ & $14 \mathrm{~h}$ & $15 b$ & $18 j$ & 90 & 55 & 80 & 54 \\
\hline
\end{tabular}

a: Results for recovery and reusability of catalyst; ${ }^{\text {b }}$ : 14h:15:16:17b at molar ratio of 1:2:2:2 with the double amount of each catalyst.

Both the catalysts allowed the formation of the products with a range yield of $83-95 \%$ in short reaction times. In particular, s-BNC showed a short reaction time in all cases, despite its porosity reduction, if compared with the s-NFC porosity. Finally, the heterogeneous catalysts were successfully recovered and reused for the synthesis of the compound 18a for three times.

Very recently, Said et al. developed an heterogeneous fluoride complex between BNC and tetrabutylammonium fluoride (TBAF) that allowed to be react as highly stable and selective fluoride source for fluorination reactions [44]. Although the use of a complex could be considered as out of scope for this review, this work is very interesting since the BNC was used both in batch and in flow condition with good to excellent results, demonstrating a high stability and versatility that could justify this concise regression. In brief, they tested different polysaccharides, such as BNC, vegetable cellulose, pectine, and starch, as support 
for (TBAF), in order to find a stable and non-hygroscopic heterogeneous complex for the $\mathrm{S}_{\mathrm{N}} 2$ type fluorination reactions performed both in batch and flow conditions (Scheme 7).

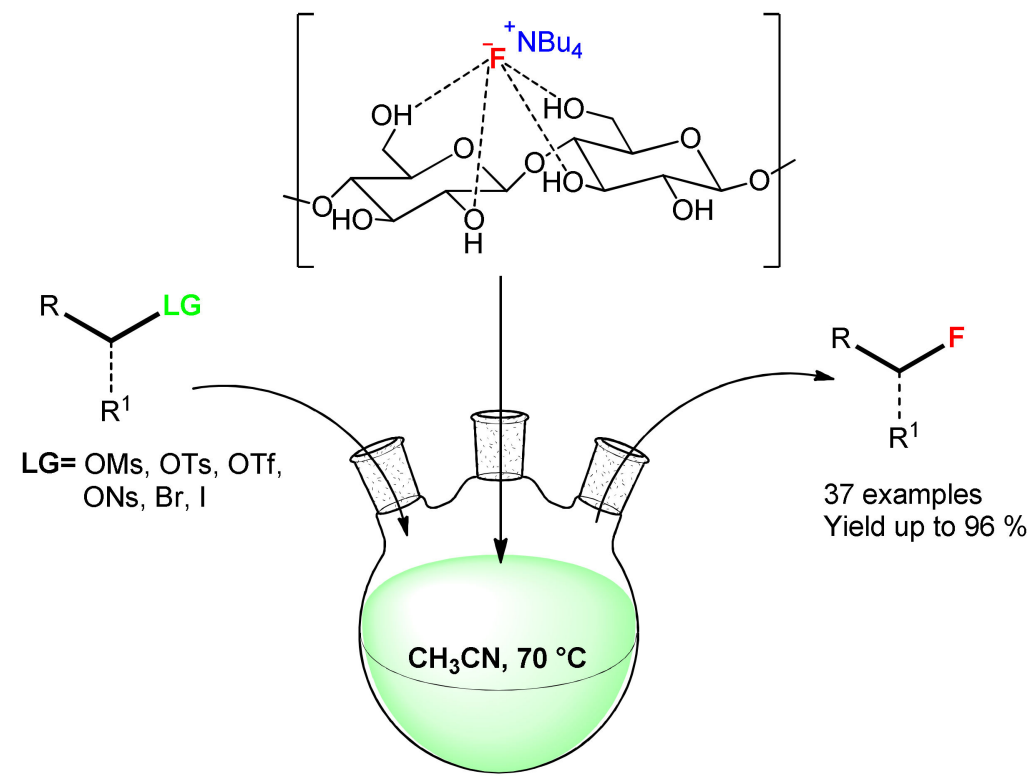

Scheme 7. Hydrogen bonded fluoride complexes for $\mathrm{S}_{\mathrm{N}} 2$ fluorination reaction.

\section{Cellulose Nanocrystals}

Cellulose Nanocrystals (CNCs) are a particular type of nanocellulose that can be easily obtained from strong acid hydrolysis of cellulose derived from biomass or bacters [45,46]. This non-toxic material is renewable, biodegradable and generally is provided at the ton scale through an industrial process carried out on wood pulp [47]. CNCs has numerous mechanical and physical-chemical properties such as: high crystalline order, well-defined size and morphology (generally ca. $5 \mathrm{~nm}$ in width and 150-250 $\mathrm{nm}$ in length) [48], high specific surface area, controllable surface chemistry and superior mechanical strength These materials can be applied in different fields, including iridescent film production [49], birefringent film production [50], reinforcing fillers in plastics and polymers [51], chiral templating in carbon and silica materials [52], hydrogels [53], aerogels [54], flocculants [55], and supercapacitors [56]. They are attractive supports for various catalytically active nanoparticles (NPs), such as Pd, Au, Ag, Fe, Cu, and $\mathrm{Ru}$ [57], thanks to stable colloidal suspensions that form $\mathrm{CNCs}$ in water and for their high specific surface area which make the material highly functionalizable. Several reactions catalyzed by cellulose nanocrystals have been developed over the past five years. Below, in the following subsections, the catalytic activity of cellulose nanocrystals suitably functionalized with inorganic and organic agents will be illustrated in detail.

\subsection{Inorganic Functionalization of Cellulose Nanocrystals and Catalytic Applications}

Moodley and co-workers have synthesized the triazolidine-3-one derivatives with the nanocellulose (CNC)/hydroxyapatite (HAp) used as catalyst in reaction between aromatic aldehydes 20a-201 and semicarbazide 19 with excellent yields [58]. The obtained results are reported in Table 3.

Notably, the aldehydes with both electron-donating and electron-withdrawing (orto, meta, and para) substituents performed efficiently under the reaction conditions in forming the corresponding target products 21a-211. 
Table 3. Triazolidine-3-one synthesis catalyzed by CNC/HAp.

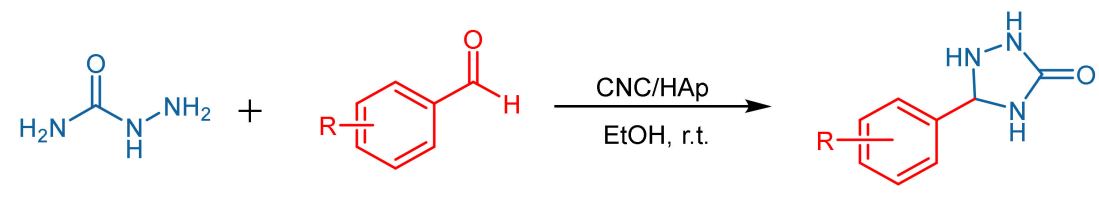

19

20a-20l

21a-21I

\begin{tabular}{cccc}
\hline Entry $^{\mathbf{a}}$ & $\mathbf{R}$ & Product & Yield (\%) \\
\hline 1 & $2-\mathrm{OMe}$ & 96 \\
2 & $4-\mathrm{OMe}$ & $\mathbf{2 1 a}$ & 96 \\
3 & $4-\mathrm{Et}$ & $\mathbf{2 1 b}$ & 95 \\
4 & $2-\mathrm{F}$ & $\mathbf{2 1 c}$ & 90 \\
5 & $2-\mathrm{Cl}$ & $\mathbf{2 1 d}$ & 94 \\
6 & $4-\mathrm{Cl}$ & $\mathbf{2 1 e}$ & 91 \\
7 & $4-\mathrm{Br}$ & $\mathbf{2 1 f}$ & 90 \\
8 & $2-\mathrm{NO}$ & 92 \\
9 & $3-\mathrm{OH}$ & $\mathbf{2 1 h}$ & 93 \\
10 & $2,3-(\mathrm{OMe})_{2}$ & $\mathbf{2 1 \mathbf { i }}$ & 94 \\
11 & $2,5-(\mathrm{OMe})_{2}$ & $\mathbf{2 1 j}$ & 94 \\
12 & $3,4-(\mathrm{OMe})_{2}$ & $\mathbf{2 1 k}$ & 91
\end{tabular}

a: Reaction conditions: semicarbazide 19 (1 mmol), aldehyde 20a-201 (1 mmol), catalyst (40 mg), ethanol (10 mL), room temperature. ${ }^{\mathrm{b}}$ : Isolated Yield.

It is possible to propose a mechanism for the cyclocondensation reaction of aldehydes and semicarbazide catalyzed by $\mathrm{CNC} / \mathrm{HAp}$ (Figure 3), in which the first step starts with nucleophilic attack of $\mathrm{NH}_{2}$ group of the semicarbazide 19 on the aldehyde carbonyl group 20a-201 that, presumably forming a short-lived zwitterionic intermediate 22a-221, becomes protonated by the acidic CNC/HAp-protic solvent combination. The cyclization is completed upon elimination of water, presumably assisted by the basic form of catalyst, passing through intermediate 24a-241, and finally, the catalyst is released back into the catalytic cycle. Lastly, when the system is reused for further applications no significant catalyst degradation was observed for at least five runs.

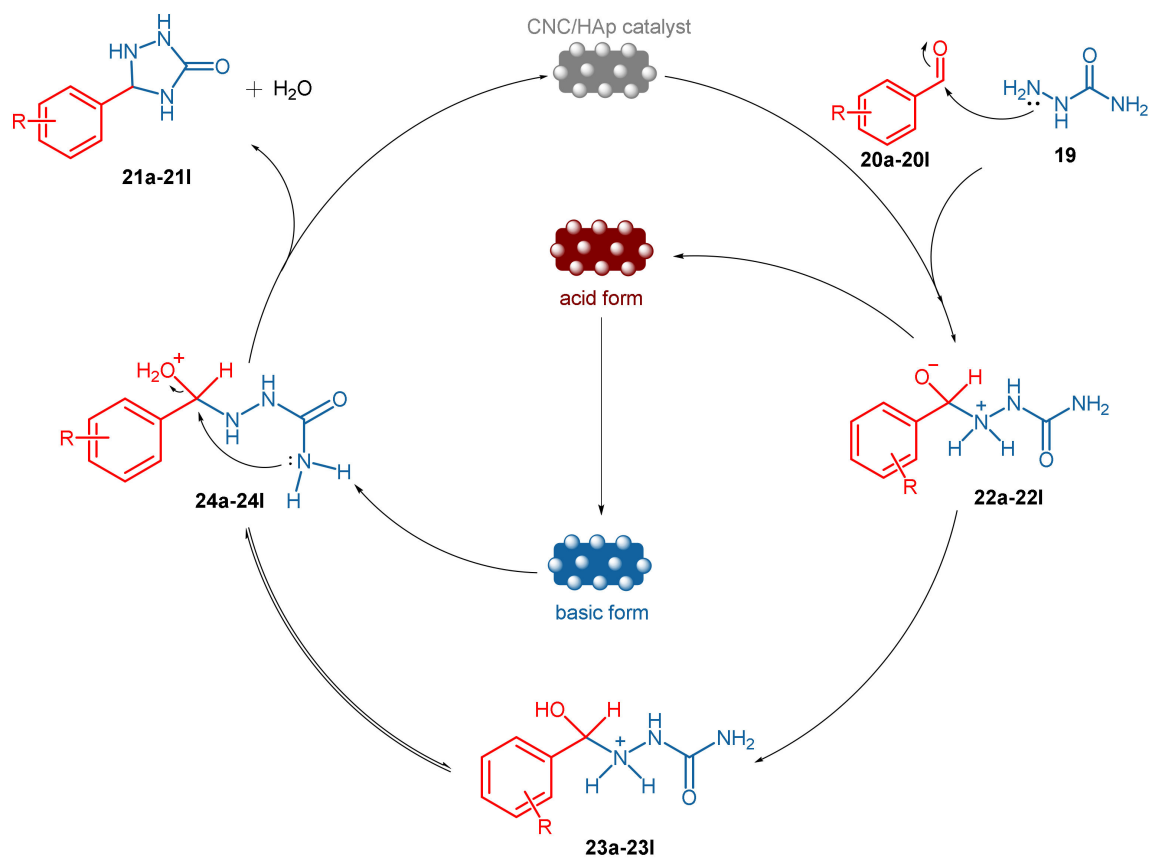

Figure 3. Proposed Mechanism for the cyclocondensation between semicarbazide 19 and aldehydes 20a-201 catalyzed by CNC/HAp. 
In 2019, a composite formed by acetylated nanocellulose and nanomagnetite was prepared and tested for the esterification reaction of oleic acid 25 to obtain the corresponding methyl ester $\mathbf{2 6}$ for biodiesel application, as shown in Scheme 8 [59].<smiles>CCCC=CCCC(C)=O</smiles>

25

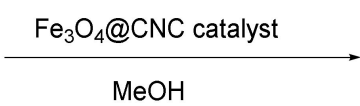

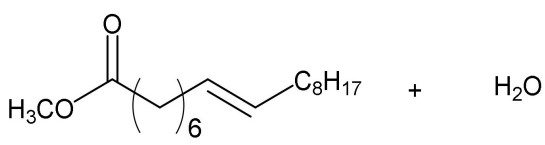

26

Scheme 8. Esterification reaction of oleic acid using cellulose-nanomagnetite $\mathrm{Fe}_{3} \mathrm{O}_{4}$ nanocomposites.

The optimal reaction conditions produced the final product in very good yields (89\%) using a quantity of catalyst of $1.5 \mathrm{wt} \%$ and a temperature at $60{ }^{\circ} \mathrm{C}$.

In recent work, Mirosanloo and co-workers developed an particular heterogenous nanocatalyst, composed of cellulose nanocrystals, palladium nanoparticles, and 2-aminopyridine (CNC-AMPD-Pd) and they proved its efficacy in the von Pechmann condensation of differently substituted phenols for the synthesis of coumarin derivatives [60]. The catalyst was synthesized starting from cellulose nanocrystals by a multi-step reaction reported in the Scheme 9.

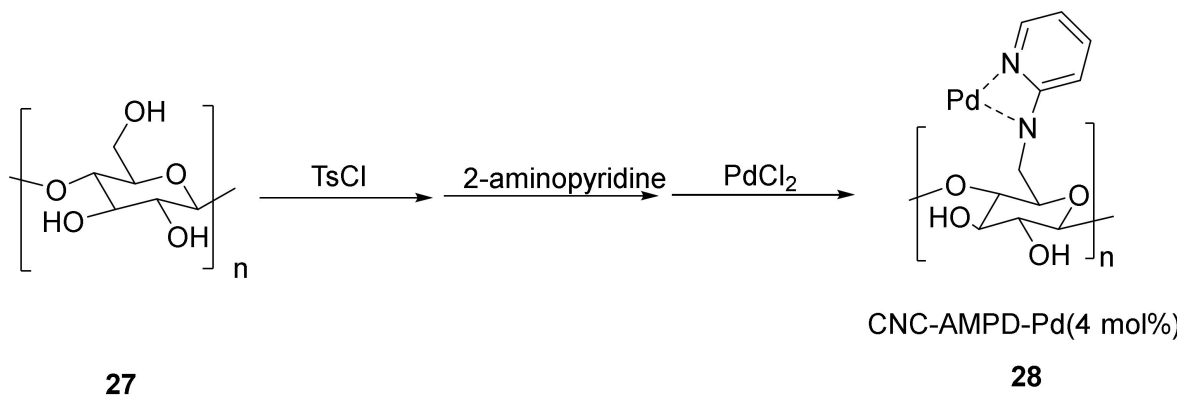

Scheme 9. Synthetic pathways for the production of CNC-AMPD-Pd catalyst.

CNC-AMPD-Pd(4 mol\%) was tested in reactions between substituted phenols and ethyl acetoacetate under solvent free conditions to obtain products in high to excellent yield as reported in Table 4.

The reaction yields are from good to excellent for all the substrates used, but the best yields were obtained with phenols carrying electro-donating substituents.

In another work nanocrystalline cellulose sulfuric acid (s-CNC) was synthesized by treating nanocellulose with chlorosulfonic acid in organic solvent [61]. The obtained catalyst was tested on the synthesis of polyhydroxy pyrimidine-fused heterocyclic compounds (PPFHs), starting from different carbohydrates 32-34, different amines 35-37, and barbituric acid 38 by a multicomponent reaction (Scheme 10).

\section{Carbohydrates}

$(+)$-D-glucose, $\quad 32$

$(+)$-D-galactose, $33+$

$(+)$-D-manose, 34

\section{Amines}

$4-\mathrm{BrC}_{6} \mathrm{H}_{4} \quad 35$

$4-\mathrm{OHC}_{6} \mathrm{H}_{4}, 36$

$\mathrm{CH}_{2} \mathrm{C}_{6} \mathrm{H}_{5}, 37$

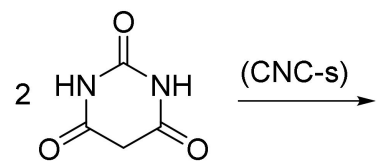

38<smiles></smiles>

$39-47$

Scheme 10. Synthesis of polyhydroxy pyrimidine-fused heterocycles(PPFHs) catalyzed by s-CNC. 
Table 4. Pechman condensation of substituted phenols $29 \mathrm{a}-29 \mathrm{~m}$ with ethylacetoacetate 30 using CNC-AMPD-Pd(4 mol\%).

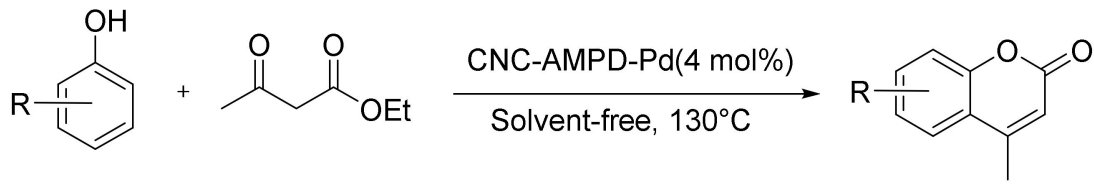

$29 a-29 m$

30

31a-31m

\begin{tabular}{|c|c|c|c|c|}
\hline Entry & Phenols 29a-29m & Reaction Time (h) & Products $31 \mathrm{a}-31 \mathrm{~m}$ & Yield $(\%)^{a}$ \\
\hline 1 & & 2 & & 94 \\
\hline 2 & & 3 & & 96 \\
\hline 3 & & 2 & & 97 \\
\hline 4 & & 1.5 & & 95 \\
\hline 5 & & 0.5 & & 92 \\
\hline 6 & & 0.5 & & 95 \\
\hline 7 & & 2 & & 90 \\
\hline 8 & & 3 & & 89 \\
\hline 9 & & 2 & & 87 \\
\hline 10 & & 7 & & 45 \\
\hline 11 & & 3 & & 86 \\
\hline 12 & & 6 & & 84 \\
\hline 13 & & 6 & & 85 \\
\hline
\end{tabular}

a: Yields are referred to isolated product after chromatography. 
The reaction was tested using different amount of the catalyst, different solvents, and different temperature. The products were obtained in short times (60-240 min) and with good yields (44-90\%). The hypothesized mechanism consists in the activation of the carbonyl group of the carbohydrate by the nanocatalyst that is successively attacked by the enolic form of the barbituric acid through a Knoevenagel condensation, to produce the first intermediate. The latter is attacked by another molecule of barbituric acid by a conjugate addition followed by a dehydration to produce the second intermediate. The elimination of water leads this intermediate to a cyclization to give the final substrate that after the reaction with the amine produces the dehydrated final product.

\subsection{Catalytic Trasformation of Inorganic Compounds for Environmental Purposes}

An et al., in 2017 [62], developed a ternary composite consisting of cellulose nanocrystal (CNC)/ hexadecyltrimethylammonium bromide (CTAB)/silver nanoparticle (AgNP) used as a catalyst for reduction of 4-nitrophenol 2. The latter is a typical polluting compound generally present in industrial and agricultural wastewater and even just a shortterm inhalation can cause serious health problems such as chest pains, migraines, vomiting, stomach pain, cyanosis, and drowsiness. AgNPs immobilized on CTAB-adsorbed CNC have higher catalytic efficiency towards the reduction of 4-nitrophenol 2 to 4-aminophenol 6, compared to the control AgNPs and CNC/Ag samples. The improved catalytic performance of AgNPs immobilized on CTAB-adsorbed CNC was attributed to the better dispersity and narrow distribution of silver nanoparticles in the catalytic system thanks to both surfactant ability of the alkyl chain of CTAB that favors hydrophobic interactions with nanoparticles and quaternary ammonium group that increases hydrophilic interaction with CNC. The resulting ternary nanocomposite was applied for highly efficient catalytic reduction of 4-nitrophenol (4-NP) 2 to 4-aminophenol (4-AP) 6. The composite was prepared using cellulose nanocrystals obtained from cellulose pulp subjected to acid hydrolysis using $64 \mathrm{wt} \%$ sulfuric acid. The resulting CNC was dispersed in water by the application of ultrasound and, subsequently, the surfactant CTAB at $\mathrm{pH}=4.5$ was introduced. The loading of the nanoparticles on the composite was favored by the introduction of silver nitrate which was subsequently reduced to silver NPs using $\mathrm{NaBH}_{4}$. It should be stressed that novel small-sized molecules behaving as amphiphiles are currently being studied thanks to their ability to form ionic liquids [63]. Such molecules, belonging to alkylphosphate, alkylamine [64], or carboxylic acids [65], are stimulating great interest due, for instance, to the peculiar self-assembly that they can trigger [66]. For this reason we believe that interesting uses / applications can be foreseen if such amphiphiles are used with nanoparticles, as for the example given for CTAB/AgNPs. It should be also said that silver nanoparticles can be easily prepared in conjunction with titania in an interesting nanocomposite with metal-semiconductor junction, which can have, obviously, particular electronic properties [67].

In any case, in the work reported by An et al. [62] the reduction of 4-NP 2 with $\mathrm{NaBH}_{4}$ was applied as model reaction to determine the catalytic activity of CNC/CTAB/Ag nanohybrid composite as reported in Scheme 11.

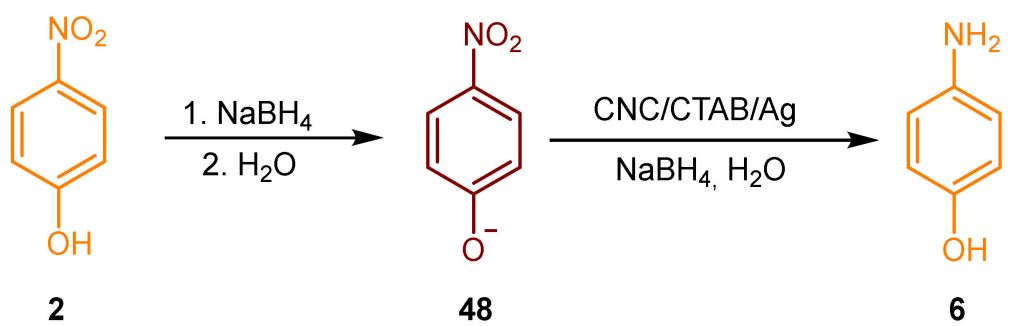

Scheme 11. Catalytic reduction of 4-nitrophenol 2 by $\mathrm{NaBH}_{4}$ in the presence of $\mathrm{CNC} / \mathrm{CTAB} / \mathrm{Ag}$ nanohybrid composite. 
Upon the addition of $\mathrm{NaBH}_{4}$ in the 4-NP 2 solution, the 4-nitrophenolate ion 48 is generated. Then, after the addition of $\mathrm{CNC} / \mathrm{CTAB} / \mathrm{Ag}$ nanohybrid composite, the anion specie is reduced to amino compound 6 . The results revealed that $\mathrm{CNC} / \mathrm{CTAB} / \mathrm{Ag}$ nanomaterial possessed the high catalytic activity for the 4-nitrophenol reduction, compared with those of unsupported Ag NPs and CNC/Ag nanocomposite, thanks to the uniformly dispersed Ag NPs with narrow size distribution. The catalytic activity $\left(545 \mathrm{~h}^{-1}\right)$ and pseudo-first order rate constant $\left(\mathrm{k}=1.6 \times 10^{-3} \mathrm{~s}^{-1}\right)$, were determined for the CNC/CTAB/Ag nanohybrid composite and these results indicated that the system has great potential in catalytic treatment of industrial and agricultural wastewater.

Another catalyst used for reduction of 4-nitrophenol 2 was synthesized by Zhang et al. in 2018 [68]. A simple and performant one-pot synthesis of well-dispersed hollow $\mathrm{CuFe}_{2} \mathrm{O}_{4}$ nanoparticles ( $\left.\mathrm{H}-\mathrm{CuFe}_{2} \mathrm{O}_{4} \mathrm{NPs}\right)$ in the presence of cellulose nanocrystals (CNC) as the support was described in this study. Based on the one-pot solvothermal condition control, magnetic $\mathrm{H}-\mathrm{CuFe}_{2} \mathrm{O}_{4}$ nanoparticles were in situ grown on the $\mathrm{CNC}$ surface uniformly. The catalytic activity of $\mathrm{H}-\mathrm{CuFe}_{2} \mathrm{O}_{4} / \mathrm{CNC}$ was verified in the reduction of 4-NP 2 (Scheme 12).

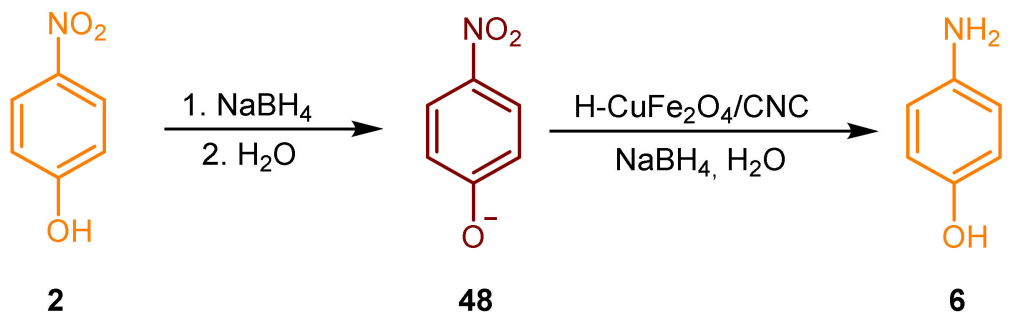

Scheme 12. Catalytic reduction of 4-nitrophenol by $\mathrm{NaBH}_{4}$ in the presence of $\mathrm{H}-\mathrm{CuFe}_{2} \mathrm{O}_{4} / \mathrm{CNC}$ composite.

The catalytic system exhibited an excellent performance compared to classical $\mathrm{CuFe}_{2} \mathrm{O}_{4}$ NPs, which was attributed to the introduction of $\mathrm{CNC}$ and the special hollow mesostructure of $\mathrm{H}-\mathrm{CuFe}_{2} \mathrm{O}_{4} \mathrm{NPs}$. In addition, the $\mathrm{HCuFe}_{2} \mathrm{O}_{4} / \mathrm{CNC}$ was recovered and reused for at least 10 times in the corresponding reactions without significant deactivation in the catalytic activity, confirming relatively high stability.

Moreover, Dhar and co-workers [64] used this catalyst for the reduction of 4-nitrophenol 2 into 4-aminophenol 6 as indicated in Scheme 13, observing quantitative conversion as also proved by UV-visible absorbance analysis.

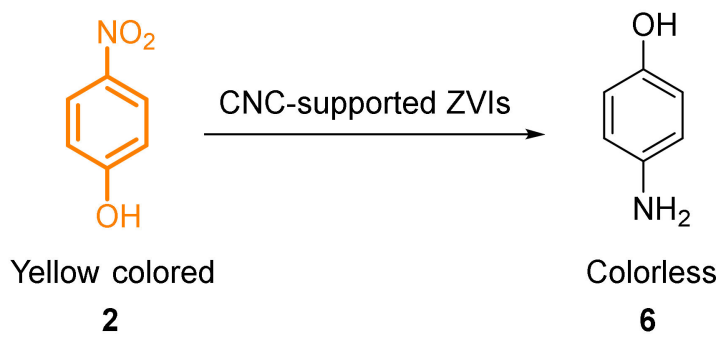

Scheme 13. Conversion of 4-AP 6 to 4-NP 2 catalyzed by CNC-supported zerovalent iron nanoparticles (ZVIs).

Another magnetic composite based on $\mathrm{MnFe}_{2} \mathrm{O}_{4}$ / cellulose nanocrystal was synthesized in 2018 for the catalytic decomposition of methylene blue $\mathbf{1}$ (MB) [69]. The nanocomposite was prepared starting from the cellulose hydrolysis for nanocellulose preparation. The obtained $\mathrm{CNC}$ was mixed with $\mathrm{MnCO}_{3}$ and $\mathrm{FeCl}_{3} \cdot 6 \mathrm{H}_{2} \mathrm{O}$ under alkaline conditions. The resulting material, namely $\mathrm{MnFe}_{2} \mathrm{O}_{4} / \mathrm{CNC}$, displayed high specific surface area and small particle dimension. It showed a higher catalytic activity than $\mathrm{MnFe}_{2} \mathrm{O}_{4}$ for the decomposition of $\mathrm{MB} 1$ in $\mathrm{H}_{2} \mathrm{O}_{2}$ solution. Furthermore, $\mathrm{MnFe}_{2} \mathrm{O}_{4} / \mathrm{CNC}$ demonstrated a high 
recovery on application of a magnet in the reaction system, which suggests great potential for wastewater purification.

Cellulose nanocrystals obtained from renewable bamboo pulp were used by Dhar and co-workers as a support for zerovalent iron nanoparticles (CNC-supported ZVIs), for multiple applications [70]. They proved that CNC-supported ZVI catalyst can be used for wastewater remediation for the decomposition of MB 1 . The decomposition was proven to be almost quantitative by UV-visible absorbance analysis. The hypothesized decomposition products, suggested by GC-MS studies, was reported in the following scheme (Scheme 14).

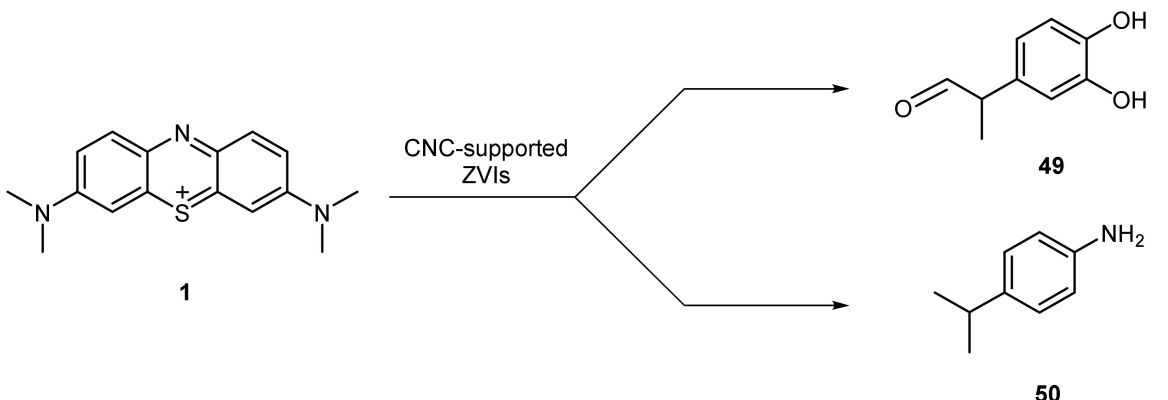

Scheme 14. Hypothesized decomposition pathways of methylene blue $\mathbf{1}$.

\subsection{Synthetic Applications of CNCs Grafted with Inorganic Catalysts}

Goswami and Das have synthesized cellulose impregnated copper nanoparticles ( $\mathrm{CNC} / \mathrm{CuNPs}$ ) used as heterogeneous catalyst for aza-Michael reactions, involving open chained as well as cyclic secondary amines and vinylic compounds directly bonded at electron-withdrawing group, to synthesize $\mathrm{N}, \mathrm{N}$-disubstituted 3-aminopropanoate esthers or N,N-disubstituted 3-aminopropanenitriles (Table 5) [71].

Table 5. $a z a$-Michael reaction between different amines and electron deficient vinylic compounds.

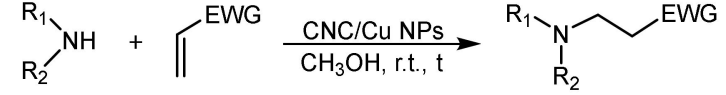

$$
\begin{aligned}
& \text { 51a-51f 52-53 54a-54f, 55a-55f }
\end{aligned}
$$

\begin{tabular}{|c|c|c|c|c|c|}
\hline Entry $^{a}$ & Amine 51a-51f & Vinylic Compound 52-53 & Product 54a-54f, 55a-55f & Timet (h) & Yield (\%) \\
\hline 1 & & DOMe & coome & 0.75 & 93 \\
\hline 2 & & & & 1 & 90 \\
\hline 3 & & & & 1.5 & 92 \\
\hline 4 & & & & 1.5 & 88 \\
\hline 5 & & & & 3.5 & 82 \\
\hline 6 & & & & 2 & 93 \\
\hline 7 & & & & 1.5 & 88 \\
\hline 8 & & & & 0.75 & 95 \\
\hline 9 & & & & 0.75 & 95 \\
\hline 10 & & & No product & 24 & - \\
\hline 11 & & $\pi^{\mathrm{CN}}$ & No product & 24 & - \\
\hline
\end{tabular}

a 1.1 mmoles of amine 51a-51f react with 1.0 mmole of vinylic compound 52-53. Mass of Methyl acrylate taken is $86.09 \mathrm{mg}$ and mass of Acrylonitrile taken is $53.06 \mathrm{mg}$. iPr is isopropyl group and $\mathrm{Bn}$ is benzyl group. 
The heterogeneous catalyst demonstrated excellent yield (82-95\%) probably due to high reduction potential of copper (indicating strong oxidizing character) which ensures greater compatibility with electron rich groups like amines. However, it was found to be totally inert when used in the case of aromatic amines (Table 5, entries 10 and 11). Finally, the catalyst can be easily recovered from the reaction mixture and reused several times without any significant loss of activity.

In 2017, Chetia et al. used CNC/CuNPs to synthesize a series of 1,4-disubstituted 1,2,3triazoles $\mathbf{6 7 - 8 0}$ by azide-alkine cycloaddition carried out in glycerol, an environmentally benign solvent, with reaction yields ranging from $68 \%$ to $99 \%$ [72]. In particular, 1,2,3triazoles are five-member $\mathrm{N}$-heterocyclic compounds bearing three nitrogen atoms in the ring that can be easily synthesized in regioselective and eco-friendly way [73-76], giving products with notable biological activities [77-79]. Generally, 1,3-dipolar cycloaddition reaction, are considered a useful approach for the synthesis of bioactive heterocyclic compounds $[80,81]$, sometimes enhancing the biological value already possessed by the precursors involved [82]. However, the results obtained from Chetia and co-workers are summarized in Table 6.

Table 6. CuNP-CNC-catalyzed 1,3-dipolar cycloaddition reaction between azides and alkyne.

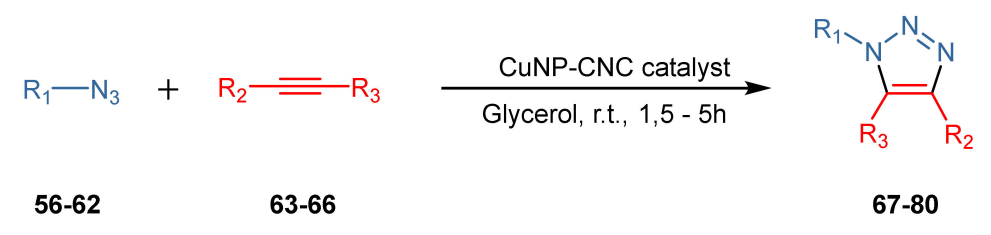

\begin{tabular}{|c|c|c|c|c|c|c|}
\hline Entry $^{a}$ & $\mathbf{R}_{1}$ & $\mathbf{R}_{2}$ & $\mathbf{R}_{3}$ & Product & Time, t (h) & Yield $(\%)$ \\
\hline 1 & $\mathrm{Bn}$ & $\mathrm{Ph}$ & $\mathrm{H}$ & 67 & 1.5 & 99 \\
\hline 2 & $\mathrm{Ph}$ & $\mathrm{Ph}$ & $\mathrm{H}$ & 68 & 1.5 & 98 \\
\hline 3 & 4-Br-Ph & $\mathrm{Ph}$ & $\mathrm{H}$ & 69 & 4 & 70 \\
\hline 4 & 4-Cl-Ph & $\mathrm{Ph}$ & $\mathrm{H}$ & 70 & 4 & 69 \\
\hline 5 & 4-MeO-Ph & $\mathrm{Ph}$ & $\mathrm{H}$ & 71 & 2 & 98 \\
\hline 6 & 4-CN-Ph & $\mathrm{Ph}$ & $\mathrm{H}$ & 72 & 4 & 68 \\
\hline 7 & $\mathrm{C}_{8} \mathrm{H}_{17}$ & $\mathrm{Ph}$ & $\mathrm{H}$ & 73 & 2 & 97 \\
\hline 8 & 4-Br-Ph & $\mathrm{C}_{4} \mathrm{H}_{9}$ & $\mathrm{H}$ & 74 & 4.5 & 82 \\
\hline 9 & $\mathrm{Bn}$ & $\mathrm{C}_{4} \mathrm{H}_{9}$ & $\mathrm{H}$ & 75 & 3.5 & 83 \\
\hline 10 & $\mathrm{Ph}$ & $\mathrm{C}_{4} \mathrm{H}_{9}$ & $\mathrm{H}$ & 76 & 1.5 & 99 \\
\hline 11 & $\mathrm{Bn}$ & $\mathrm{CH}_{2} \mathrm{OH}$ & $\mathrm{H}$ & 77 & 2.5 & 71 \\
\hline 12 & 4-Br-Ph & $\mathrm{CH}_{2} \mathrm{OH}$ & $\mathrm{H}$ & 78 & 3.5 & 72 \\
\hline 13 & $\mathrm{Ph}$ & $\mathrm{CH}_{2} \mathrm{OH}$ & $\mathrm{H}$ & 79 & 3 & 93 \\
\hline 14 & $\mathrm{Ph}$ & COOMe & COOMe & 80 & 3.5 & 89 \\
\hline
\end{tabular}

${ }^{a}$ : Reaction is performed with 1 mmole of azide 56-62, 1.1 mmoles of alkyne 63-66 and 1.05 mol\% of heterogeneous catalyst in $2 \mathrm{~mL}$ of glycerol at room temperature. ${ }^{\mathrm{b}}$ : Isolated Yield.

The application of this kind of reaction, using CuNPs/CNC as heterogeneous catalyst, was investigated with different azides and alkynes and the best conditions were found at room temperature. Aromatic and aliphatic terminal alkynes readily reacted with the diverse azides to give the corresponding 1,4-disubstituted 1,2,3-triazoles 67-80 in good to excellent yields (68-99\%). High reaction yields are observed when phenylacetylene reacts with aromatic or alkylic azide (entries $2,10,13,14$ ). The recyclability of CuNPs/NC was investigated in the cycloaddition of phenylacetylene 63-66 and benzylazide 56 and after each cycle the catalyst was recovered by simple filtration and reused after washing with organic solvent. About $90 \%$ of the original activity was obtained even after the fifth run. In a work carried out by Dutta and co-workers, $\mathrm{Cu}$ nanoparticles were immobilized on nanocellulose, producing CuNPS/CNC material that was tested as heterogenous catalyst for the oxidation of sulfides in mild reaction conditions, good yields, and discrete reaction time. Sulfides are versatile compounds also present in nature, with important pharmacological activity [83], which can be synthesized through easy approaches [84].

The results are collected in Table 7 [85]. 
Table 7. Oxidation of sulfides by CuNPS/CNC in ethanol.

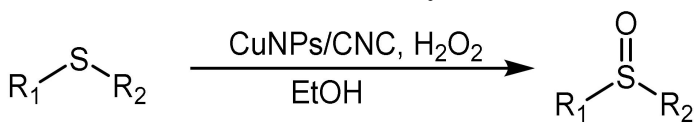

$81 a-81 f \quad 82 a-82 f$

\begin{tabular}{|c|c|c|c|c|}
\hline Entry & Substrates 81a-81f & Products $82 a-82 f$ & Time (h) & Yield (\%) ${ }^{a}$ \\
\hline 1 & & & 2 & 99 \\
\hline 2 & & & 5 & 95 \\
\hline 3 & & & 12 & 73 \\
\hline 4 & & & 12 & 65 \\
\hline 5 & & & 2 & 96 \\
\hline 6 & & & 2.5 & 95 \\
\hline
\end{tabular}

The developed catalyst was also tested on the oxidation of different alcohols using TEMPO (2,2,6,6-tetramethyl-1-piperidinyloxy) as nitroxyl radical and the results are reported in Table 8.

Table 8. Oxidation on different alcohols by CuNPs/NC and TEMPO.

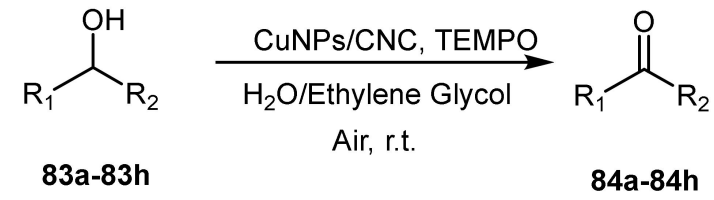

Entry Substrates 83a-83h

a: Isolated yield.

The reaction outcome was excellent predominantly with para-substituted aromatic alcohols. Lower yield was observed for saturated and unsaturated aliphatic alcohols probably due to the steric hindrance of the long alkyl chains. These latter, generally, are introduced on organic molecules to enhance the biological activity [86]. Nanocomposites with diameters less than $100 \mathrm{~nm}$, used as heterogeneous catalysts, are difficult to separate from the reaction mixture. Therefore, the adsorption of magnetic nanoparticles on their surface furnish a facile-apply magnetic material that can be recovered by simple attraction 
from an external magnet [87]. In this context, Mirjalili and Imani synthesized a magnetic bio-based nanocatalyst, signed as $\mathrm{Fe}_{3} \mathrm{O}_{4} @ \mathrm{CNC} / \mathrm{BF}_{0.2}$ (where $\mathrm{BF}$ is referred to $\mathrm{BF}_{3} \mathrm{OEt}_{2}$ ) for the synthesis of aryl-2,3-dihydro- $1 \mathrm{H}$-perimidines $\mathbf{8 7 a - 8 7 1}$ by cyclocondensation of 1,8-diaminonaphthalene $\mathbf{8 6}$ with aromatic aldehydes 85a-851 (Table 9) [88].

Table 9. Synthesis of aryl-2,3-dihydro-1H-perimidine derivatives with $\mathrm{Fe}_{3} \mathrm{O}_{4} @ \mathrm{CNCs} / \mathrm{BF}_{0.2}$ used as catalyst.

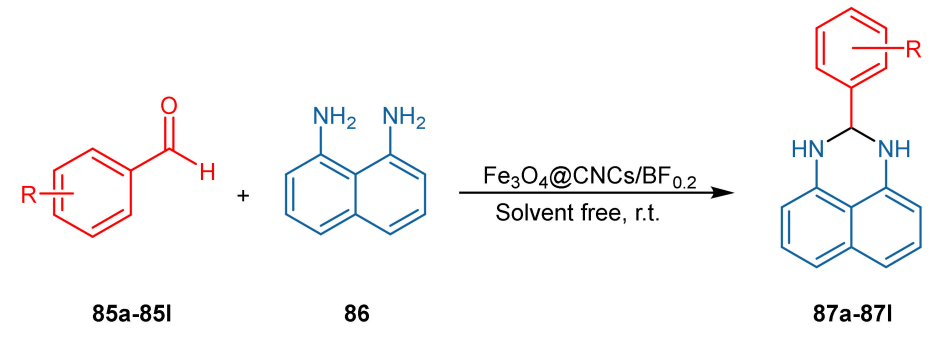

\begin{tabular}{ccccc}
\hline Entry ${ }^{\mathbf{a}}$ & $\mathbf{R}$ & Time (min) & Product 87a-871 & Yield (\%) \\
\hline 1 & $\mathrm{H}$ & 5 & $\mathbf{a}$ & 98 \\
2 & $4-\mathrm{OMe}$ & 15 & $\mathbf{b}$ & 91 \\
3 & $4-\mathrm{NMe}_{2}$ & 15 & $\mathbf{c}$ & 86 \\
4 & $2,4-(\mathrm{OMe})_{2}$ & $\mathbf{d}$ & 75 \\
5 & $3,4-(\mathrm{OMe})_{2}$ & 15 & $\mathbf{e}$ & 92 \\
6 & $4-\mathrm{Cl}$ & 15 & $\mathbf{f}$ & 96 \\
7 & $4-\mathrm{COOH}_{2}$ & $\mathbf{g}$ & 99 \\
8 & $2-\mathrm{NO}_{2}$ & $\mathbf{h}$ & 94 \\
9 & $3-\mathrm{NO}_{2}$ & 10 & $\mathbf{i}$ & 96 \\
10 & $4-\mathrm{NO}_{2}$ & 12 & $\mathbf{j}$ & 99 \\
11 & $2,3-(\mathrm{OMe})_{2}$ & 10 & $\mathbf{k}$ & 85 \\
12 & $2,3-(\mathrm{Cl})_{2}$ & 10 & $\mathbf{1}$ & 88
\end{tabular}

In Table 9, it is possible to observe good and high yields of products under very mild and green conditions and short reaction time. Moreover, the presence of electronwithdrawing groups on the aromatic ring of the aldehyde favors the formation of the product with higher yields than the presence of electron-donating groups. Other advantages of $\mathrm{Fe}_{3} \mathrm{O}_{4} @ \mathrm{CNCs} / \mathrm{BF}_{0.2}$ as a catalyst are biodegradation, reusability, environmental friendliness, and easy separation with an external magnet. The recyclability of the catalyst was also investigated on the model reaction (Table 9, entry 1), reusing it at least four times with little loss of catalytic activity. The proposed mechanism is shown in Figure 4 .

The proposed mechanism consists of a series of stages. At first, $\mathrm{Fe}_{3} \mathrm{O}_{4} @ \mathrm{CNCs} / \mathrm{BF}_{0.2}$ as Lewis acid attacks the carbonyl group of the aldehyde 85a-851, generating the imine intermediate 92a-921. The latter cyclizes by intramolecular nucleophilic attack of amino group present on the naphthalene backbone, affording the products 87a-871. In summary, this method offers different advantages including easy work-up, high yields in short time and the heterogeneous catalyst is eco-friendly because it can be reused for numerous cycles.

Liu et al. proposed new catalysts based on cellulose nanocrystals supported dirhodium (II) to be investigated on the cyclopropanation of styrene with EDA [89]. The catalytic systems were abbreviated in CNC- $\mathrm{Rh}_{2}-0.5 \mathrm{~d}, \mathrm{CNC}-\mathrm{Rh}_{2}-2.5 \mathrm{~d}$, and CNC- $\mathrm{Rh}_{2}-4.5 \mathrm{~d}$. Among these species CNC- $\mathrm{Rh}_{2}-4.5 \mathrm{~d}$ was selected for testing it on the model reaction because it showed the highest concentration of catalytic sites. The reaction Scheme and the yields of the products are reported in Table 10. 
<smiles>[R7]c1ccc(C(=O)CB(C)OC(C)C)cc1</smiles><smiles></smiles>

$\mathrm{O}=\mathrm{Fe}_{3} \mathrm{O}_{4} @ \mathrm{CNC}$

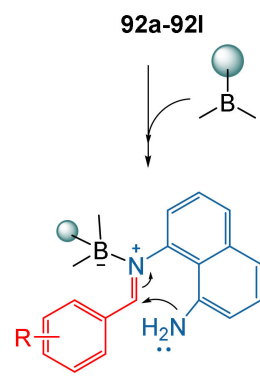

93a-93!

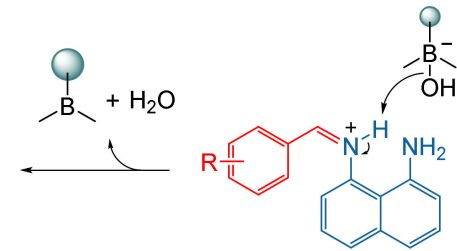

91a-91I

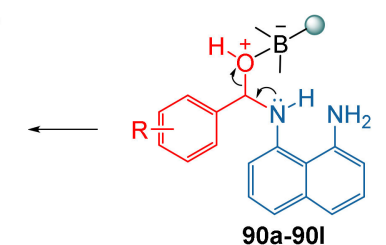

90a-90I

Figure 4. Proposed Mechanism for the synthesis of aryl-2,3-dihydro- $1 \mathrm{H}$-perimidines $\mathbf{8 7 a}-\mathbf{8 7 1}$ catalyzed by $\mathrm{Fe}_{3} \mathrm{O}_{4} @ \mathrm{CNCs} / \mathrm{BF}_{0.2}$.

Table 10. Reaction of styrene with EDA catalyzed by CNC-supported rhodium catalyst.

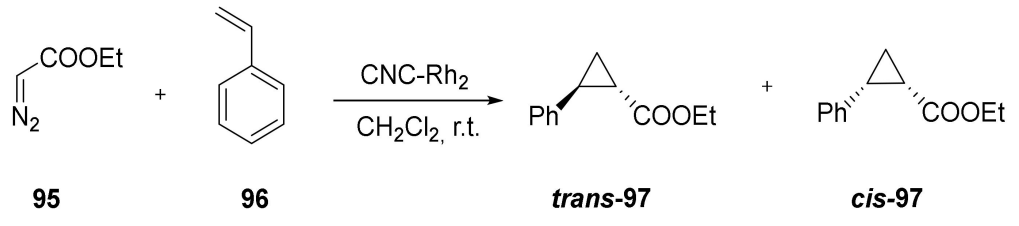

\begin{tabular}{ccccc}
\hline Entry $^{\text {a }}$ & Reaction Time & Cis-97 Yield (\%) & Trans-97 Yield (\%) & Total Yield (\%) \\
\hline 1 & 15 & 20 & 22 & 42 \\
2 & 30 & 21 & 29 & 50 \\
3 & 45 & 28 & 34 & 62 \\
4 & 60 & 29 & 35 & 64 \\
5 & 120 & 33 & 39 & 72 \\
6 & 180 & 34 & 40 & 74 \\
\hline
\end{tabular}

a: The reaction was tested using the $\mathrm{CNC}-\mathrm{Rh}_{2}-4.5 \mathrm{~d}$ catalyst.

Finally, the recyclability of the catalyst $\mathrm{CNC}-\mathrm{Rh}_{2}-4.5 \mathrm{~d}$ was also evaluated, demonstrating that the yields remained almost unchanged after three cycles.

\section{Cellulose Nanofibers}

With the term cellulose nanofibers (CNFs), also named cellulose nanofibrils, nanofibrillated cellulose, and nanofibrous cellulose, is intended a wide family of nanocelluloses characterized by a nanometric length comprised between 50 and $3000 \mathrm{~nm}$ and a width from 5 to $50 \mathrm{~nm}$. Introduced in early 1980s [90,91], CNFs are obtained from the mechanochemical treatment of cellulosic biomasses, and presents a lower degree of crystallinity with respect to cellulose nanocrystals or bacterial nanocellulose. In addition, they also show interesting mechanical and physicochemical properties: large specific surface area, high strength, and an easy chemically tunable surface. 
At the beginning, CNFs were obtained from the simple delamination of delignified and bleached pulps; however, this treatment has been shown to be very expensive in terms of energy consumption, and various other mechanical procedures have been proposed to improve this aspect and making the industrial production of CNFs much more affordable [92-94]. Numerous other procedures have been also developed in order to improve further the production of CNFs and can be categorized into two main families: swelling induced by charged groups, enzymes [95,96], or mild acid treatments. In the first case, the main procedures employed to introduce charged groups in the polymeric backbone include chemical oxidation performed via TEMPO (2,2,6,6-tetramethyl piperidinyloxy) [97,98] and carboxymethylation [99].

In this section, we will focus on the catalytic applications of inorganic and organicfunctionalized CNFs. For a broader review of the production and applications of CNFs, the reader can refer to $[97,100-102]$.

\subsection{Inorganic-Functionalized CNFs Employed in Catalysis}

The inorganic functionalization of CNFs for catalytic applications is mainly devoted to the use of CNFs as supporting materials for the growth of nanoparticles (NPs). The NPs mainly used as heterogeneous catalysts are made up including noble and transition metals such as $\mathrm{Bi}, \mathrm{Al}, \mathrm{Mo}, \mathrm{Ag}, \mathrm{Fe}, \mathrm{Ti}, \mathrm{Ru}, \mathrm{Cu}, \mathrm{Co}, \mathrm{Pt}, \mathrm{Pd}, \mathrm{Ni}$, and $\mathrm{Au}$, often in their oxidized state or in presence of another element (i.e., $\mathrm{Ni} / \mathrm{Fe}, \mathrm{CoS}, \mathrm{CuS}$, etc.). The main fields of application reported in literature comprise catalytic degradation of environmental pollutants, electrocatalytic conversion of small molecules, photocatalysis and organic synthesis.

\subsubsection{Catalytic Transformation of Organic Compounds for Environmental Purposes}

Chemical transformation of organic and inorganic pollutants can be a useful strategy for pollutants removal in aqueous systems. In this sense, Ag-based CNF composite proved to be an efficient medium for the conversion of diverse chemicals having high environmental impact. The principal applications of Ag NP-decorated CNFs consist of degradation of dyes in aqueous systems or reduction of nitrophenolic derivatives. One of the first evidences about aqueous dyes degradation was reported in literature by Jang and co-workers with the evaluation of the role of a deacetylated-CNF template included in AgNP growth and the efficacy of the composite in methylene blue (MB) reduction [103]. The composite was tested evaluating the degradation of MB measuring the intensity of the main absorption peak of the dye at $668 \mathrm{~nm}$, revealing that the full dye degradation took place in 1-10 min.

Recently, Zhang and collaborators developed a new CNF-hydrogel poly(ethylene imine)-based material functionalized with Ag NPs [104]. The material was tested on catalytic continuous discoloration of aqueous cationic and anionic dyes in batch and in flow test obtaining an efficiency greater than $98 \%$ maintained for up to 10 cycles of employ. The possibility of using this membrane material under high water flux $\left(5 \times 10^{4} \mathrm{~L} \cdot \mathrm{m}^{-2} \mathrm{~h}^{-1}\right)$ allowed the treatment of considerable volumes of water.

As for nitrophenols degradation, one of the first evidences was reported by Heidari [105]. In this reported case, the composite was prepared adsorbing Ag NPs on hydrogels of CNFs, which was a non-inert template since it acted also as a stabilizer and reducing agent toward the pollutants employed. Its catalytic potency was evaluated, in particular, toward the degradation of 2 to 6 (Table 11), obtaining values of rate constants up to $46.6 \times 10^{-3} \mathrm{~s}^{-1}$ and catalytic activities up to $2.33 \mathrm{~s}^{-1} \mathrm{~g}^{-1}$. In another work, Gopiraman and collaborators realized Ag NP-decorated CNFs that were tested toward the reduction of both 2 and 5 in water. The reported rate constants for the two pollutants were, respectively, $9.05 \times 10^{-2} \mathrm{~s}^{-1}$ and $11.34 \times 10^{-2} \mathrm{~s}^{-1}$, showing very important results [106]. Successively, in 2019, they proposed a new Ag@Au bimetallic CNF composite from leaves of Moringa oleifera [107]. The catalytic performance of Ag@Au@CNFs was evaluated on a solution of nitrophenol measuring the UV-vis absorbance of the nitrophenol in the sample at different 
intervals. Table 11 summarizes the evidence reported in literature about nitrophenols (NP) reduction employing Ag NP-functionalized CNFs.

Table 11. Applications of Ag NPs@CNFs catalysts to 4-NP 2 and 2-NP 5 reduction in water.<smiles>[R]=[N+]([O-])C1=CC=CC=[C+]=C1</smiles>

$\mathrm{R}=2-\mathrm{NO}_{2}, 4-\mathrm{NO}_{2}$<smiles>Nc1ccccc1</smiles>

$\mathrm{R}=2-\mathrm{NH}_{2}, 4-\mathrm{NH}_{2}$

2,5

6, 8

\begin{tabular}{cccc}
\hline Nitrophenol (NP) & Catalyst & Rate Constant & Reference \\
\hline 2 & $\mathrm{Ag} / \mathrm{CNFs}$ hydrogel & $46.6 \times 10^{-3} \mathrm{~s}^{-1}$ & {$[105]$} \\
2 & $\mathrm{Ag} / \mathrm{CNFs}$ & $9.05 \times 10^{-2} \mathrm{~s}^{-1}$ & {$[106]$} \\
5 & & $11.34 \times 10^{-2} \mathrm{~s}^{-1}$ & \\
2 & $\mathrm{Ag} / \mathrm{Au} / \mathrm{CNFs}$ & $22.83 \times 10^{-2} \mathrm{~s}^{-1}$ & {$[107]$} \\
5 & & $15.59 \times 10^{-3} \mathrm{~s}^{-1}$ & \\
\hline
\end{tabular}

Iron too was explored as inorganic-functionalizing agent for CNF hybrid material production. Cunha Arantes and collaborators proposed an hybrid catalyst made up of CNFs and iron oxide NPs (magnetite) [108]. This catalyst was employed in MB degradation in a Fenton-like process which degraded 100\% of dye in $180 \mathrm{~min}$. Iron-based CNF nanocatalyst was explored also using Fe elements in combination with other metals as reported by Hou, very recently [109]. In this regard, Fe was employed in combination with Co in order to obtain a metal-organic framework (MOF) adsorbed onto the surface of CNFs. This approach enabled a membrane to be obtained useful for the catalytic degradation of tetrabromobisphenol A (TBBPA), a widely dispersed brominated flame retardant (BFR) also known for its hepatotoxicity, cytotoxicity, and immunotoxicity. In this case, $\mathrm{Co} / \mathrm{Fe}$ bi-MOF/CNF composite was capable of full degradation of TBBPA in 30 min with rate constant of $0.764 \mathrm{~min}^{-1}$ and a degradation of the catalytic membrane of $60 \%$ after four cycles of treatment.

In 2018, Pd NPs were employed in the preparation of reusable CNFs water-activated shape memory aerogels [110]. The material was obtained starting from TEMPO CNFderivatives and applied for the catalytic degradation of both cationic and anionic dyes (MB 1 and Congo red) at concentration of 20 ppm, giving a discoloration efficiency comprised between 91.1 and $99.0 \%$ for five cycles of work.

Ujihara and co-workers were capable of preparing in 2018 a new composite where Pt NPs were embedded by a nanostructure of dendrimers and cellulose nanofibers [111]. In this case, the dendrimer was made up of poly (amido amine) and was covalently bonded on 2,2,6,6tetramethyl-1-piperinyloxy free radical oxidized cellulose nanofibers (TOCNFs). The prepared Pt-based composite were successfully applied to catalytic degradation of formaldehyde and 5. In 2020, a composite material made up by borate-functionalized CNFs and Pt (or Ag and $\mathrm{Au}$ ) was prepared for application in degrading of 4-nitrophenol 2 [112]. In this study, functionalized CNFs acted as reducing agents in order to obtain the NPs on their surface, giving nanospheres of diameters of $9 \mathrm{~nm}$. Their activity in 4-nitrophenol 2 degradation was quantified calculating their TOFs numbers, giving values comprised between $1038 \pm 238 \mathrm{~h}^{-1}$ (Pt NPs/CNFs suspension) and $352 \pm 34 \mathrm{~h}^{-1}$ (Ag@Pt NPs/CNF-B(1\%) film).

In 2020, other evidence about inorganic elements employed in this context were reported by Idrissi et al. [113]. In this context, the role of Co NPs on the surface of CNFs was investigated for the reduction of 4-nitrophenol 2 that was successfully reduced in $8 \mathrm{~min}$ at $25^{\circ} \mathrm{C}$. Gan and co-workers, again in 2020, focused on the role of polyoxometalate in combination with carbonized cellulose nanofibers [94]. They applied this type of 
composite on oxidative desulfurization reactions, a promising procedure for the removal of sulfur-based heterocyclic derivatives. In this work, the polyoxometalate chosen was $\left[\beta-\mathrm{SiMo}_{3} \mathrm{~W}_{9} \mathrm{O}_{40}\right]^{\mathrm{n}}$, which was loaded on the CNF's surface. The removal of dibenzothiophene, benzothiophene and 4,6-dimethyldibenzothiophene in oil was quantified, giving reduction percentages up to $99 \%$. In a similar way, Zhang et al. reported the hydroxydesulfurization of dibenzothiophenes achieved through mesoporous $\gamma-\mathrm{Al}_{2} \mathrm{O}_{3} / \mathrm{CNF}$ acting as template for MoNi NPs as catalyst; in this case, $\mathrm{k}$ and TOF parameters obtained were up to $16.9 \times 10^{-4} \mathrm{~mol} \cdot \mathrm{g}^{-1} \cdot \mathrm{h}^{-1}$ and $5.3 \mathrm{~h}^{-1}$, respectively [114].

\subsubsection{Electrocatalytic Applications of Inorganic-Functionalized CNFs}

The main application of inorganic-CNF composites in electrocatalysis involves oxygen transformations and, in particular, the so-called oxygen evolution reactions (OERs) and oxygen reduction reactions (ORRs) (Figure 5).

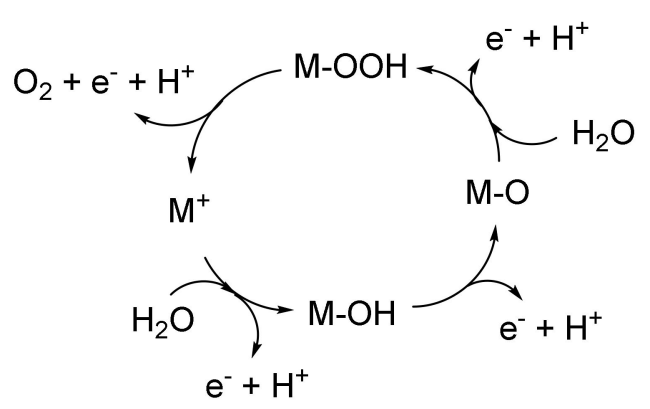

Oxygen Evolution Reaction OER

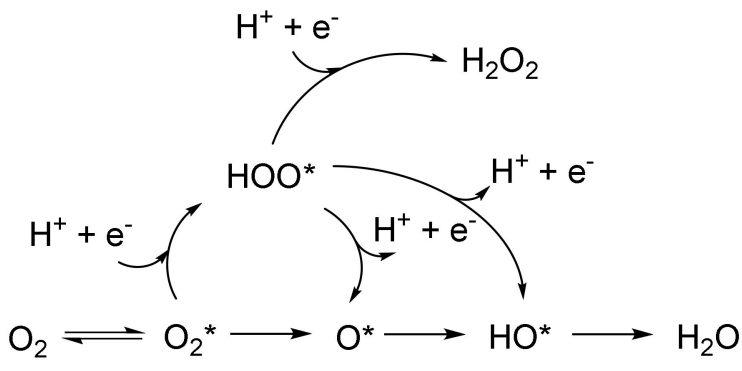

Oxygen Reduction Reaction ORR

Figure 5. Example of a typical oxygen evolution reaction (OER) and oxygen reduction reaction (ORR).

OERs are an important class of electrochemical reactions which enable the production of hydrogen from water-splitting, particularly employed in fuel cells, solar cells, and metalair batteries. In this regard, Tian and collaborators reported in 2019 the first evidence of a CNF-based template for the preparation of electrocatalysts to employ in OERs [115]. In particular, it was realized that a $\mathrm{Ni} / \mathrm{Fe} / \mathrm{CNF}$ composite where the abundance of carboxyls and hydroxyls groups present on the surface of CNFs helped the fine dispersion of the inorganic moiety. This material exhibited a very high electrocatalytic performance and an excellent long-term stability.

Subsequently, Tao and collaborators successfully employed a Ni derivative to functionalize N-doped CNFs [116], where the term "N-doped" stands for CNFs with a nitrogen content via a pretreatment with dicyandiamide. In this case, $\mathrm{Ni} @ \mathrm{Ni}_{2} \mathrm{P}$ NPs grafted onto a carbonized composite of CNFs and carbon nanotubes, taking advantage from the notable specific surface area present. The obtained catalyst enabled an overpotential of $269 \mathrm{mV}$ to be achieved, with a $1.7 \%$ decay after $20 \mathrm{~h}$ long-term test. In the same year, Tian et al. [117] developed a CoFeS@CNFs nanocomposite which achieved an overpotential of $257 \mathrm{mV}$ while delivering a current of $10 \mathrm{~mA} \cdot \mathrm{cm}^{-2}$ and decreasing by only $2.82 \%$ after $50 \mathrm{~h}$ of work.

As for ORRs, Lee et al. [118] and Meng and co-workers [119] proposed important evidence in this field of fuel cells science. In the first case, a nanocomposite based on TEMPO-oxidized N-doped porous carbon CNFs decorated with $\mathrm{Co} @ \mathrm{Co}_{3} \mathrm{O}_{4} \mathrm{NPs}$ was reported. Even in this case, a three-dimensional network of the CNF template helped the fine dispersion of the catalyst's NPs, giving performances comparable to the already-used $\mathrm{Pt} / \mathrm{C}$ catalysts. As for the other reference, a nanocomposite made up by Co NPs loaded on $\mathrm{N}$-doped CNFs was prepared. The catalyst reported notable properties, like a long-term durability, becoming an important alternative to the available $\mathrm{Pt} / \mathrm{C}$ systems. 
4.1.3. Photocalytic Applications of CNFs-Inorganic Composites for Environmental Remediation

The main photocatalytic applications of inorganic-functionalized CNFs concern the chemical transformation of organic and inorganic species considered dangerous pollutants even at low concentrations. In particular, they have been applied in the catalytic degradation of dyes, dangerous cationic metals, and antibiotics.

In 2018, Salama and co-workers prepared a composite material made up from CA$\mathrm{CNFs}$, multiwall carbon nanotubes (CNT), and $\mathrm{NH}_{2}$-functionalized $\mathrm{TiO}_{2} \mathrm{NPs}$ [120]. The so-obtained material was successfully employed in photodegradation experiments with $\mathrm{MB}$ and indigo carmine (IC), revealing degradation percentages up to $100 \%$ for both dyes. In this case, factors such as temperature, $\mathrm{pH}$, and power intensity of the UV lamp were investigated to find the best conditions. Zabihi Sahebi et al. also developed a CNF-based inorganic composite useful in photocatalytic degradation of dyes and harmful inorganic species [121]. In this case, $\mathrm{CA} /$ chitosan/single walled $\mathrm{CNT} / \mathrm{Fe}_{3} \mathrm{O}_{4} / \mathrm{TiO}_{2}$ nanofibrils were obtained via electrospinning technique and applied to the removal of $\mathrm{MB}$, Congo red, $\mathrm{Cr}(\mathrm{VI})$, and $\mathrm{As}(\mathrm{V})$. In particular, this material enabled the complete degradation of both organic and inorganic pollutants up to concentration of $100 \mathrm{mg} \cdot \mathrm{L}^{-1}$ to be achieved. For $\mathrm{Cr}(\mathrm{VI})$ and $\mathrm{As}(\mathrm{V})$, the composite showed a notable degradation percentage $(95 \%)$, while the percentage lowered to $85 \%$ for both the aza-dyes.

Another approach for $\mathrm{Cr}(\mathrm{VI})$ removal was recently proposed by Gan and collaborators [122]. They prepared a series of cellulose-derived carbon nanofibers which were then combined with bismuth oxybromide ( $\mathrm{BiOBr})$. In this case, the catalyst generated active oxidative and reductive oxygen species in situ capable of simultaneously degrading $\mathrm{Cr}(\mathrm{VI})$ and rhodamine $B(\mathrm{RhB})$ dye at an initial concentration of $10 \mathrm{mg} \cdot \mathrm{L}^{-1}$ for both species. In particular, it was established that the presence of $\mathrm{RhB}$ in the aqueous system promoted the removal efficiency of $\mathrm{Cr}(\mathrm{VI})$.

RhB was also subject of study in the study proposed by Tian and co-workers [123]. In this case, a composite where CNFs were employed to anchor Ag ions onto carbon nitride $(\mathrm{CN})$, an interesting metal-free photocatalyst. This approach guaranteed an efficient degradation of RhB and tetracycline (TC) under visible light was realized.

Other important evidence useful in dye remediation of waters was recently proposed by several authors employing bimetallic systems. In particular, Gupta and collaborators proposed a novel CNFs-based composite bearing $\mathrm{NiFe}_{2} \mathrm{O}_{4} \mathrm{NPs}$ applied to the photo-Fenton degradation of Remazol Black 5 (RB5) and nitrophenols 2 and 5, obtaining interesting results [124]. Zheng et al., on the other hand, developed a bimetallic system Co-Cu-based $\left(\mathrm{CoS}_{2}\right.$-CuS) particularly active in antibiotics degradation [125]. The drugs chosen for this study were ciprofloxacin and ofloxacin: under UV-light, at pH 5 and in $60 \mathrm{~min}$, their $\mathrm{CoS}_{2}$ CuS@CNFs novel catalyst was capable of degrading up to $98.11 \%$ and $88.0 \%$, respectively, of each compound. Zhang and co-workers [126] also recently introduced a novel bimetallic derivative for photocatalytic purposes. The realized material was a membrane consisting of CNFs-CoFe $\mathrm{O}_{4} / \mathrm{PVDF}$ (polyvinylidene fluoride) used in the cathode of a photocatalytic fuel cell (PFC). In this case, the material was capable of activating peroxymonosulfate (PMS) transformation in order to obtain sulfate radicals $\left(\mathrm{SO}_{4}{ }^{-}\right)$, hydroxyl radicals $(\mathrm{OH})$, singlet oxygen $\left({ }^{1} \mathrm{O}_{2}\right)$, and superoxide radical $\left(\mathrm{O}_{2}{ }^{-}\right)$. The species obtained took part in the subsequent degradation of berberine, an antibiotic, shading new light on PFC/PMS systems applied to water remediation. Table 12 summarizes the photocatalytic applications of inorganic-containing CNFs described in this section. 
Table 12. Resume of the photocatalytic applications of inorganic-containing CNFs.

\begin{tabular}{|c|c|c|c|c|c|}
\hline Substrate & Catalyst & Reference & Substrate & Catalyst & Reference \\
\hline MB 1 & $\begin{array}{c}\mathrm{Ag} @ \mathrm{CNFs} \\
\mathrm{TiO}_{2^{-}} \\
\mathrm{NH}_{2} @ \mathrm{CNFs} / \mathrm{CNT} \\
\mathrm{Fe}_{3} \mathrm{O}_{4} / \mathrm{TiO}_{2} @ \mathrm{CNF} / \\
\text { Chitosan/CNT }\end{array}$ & $\begin{array}{l}{[120]} \\
{[121]}\end{array}$ & $\begin{array}{c}2 \\
25\end{array}$ & $\mathrm{NiFe}_{2} \mathrm{O}_{4} @ \mathrm{CNFs}$ & [124] \\
\hline Indigo carmine & $\frac{\mathrm{TiO}_{2-}^{-}}{\mathrm{NH}_{2} @ \mathrm{CNFs} / \mathrm{CNT}}$ & [120] & $\mathrm{Cr}(\mathrm{VI})$ & $\begin{array}{c}\mathrm{Fe}_{3} \mathrm{O}_{4} / \mathrm{TiO}_{2} @ \mathrm{CNF} / \\
\text { Chitosan/CNT } \\
\mathrm{BiOBr} @ \mathrm{CNFs}\end{array}$ & $\begin{array}{l}{[121]} \\
{[122]}\end{array}$ \\
\hline $\mathrm{TC}$ & Ag/CN@CNFs & [123] & $\mathrm{As}(\mathrm{V})$ & $\begin{array}{c}\mathrm{Fe}_{3} \mathrm{O}_{4} / \mathrm{TiO}_{2} @ \mathrm{CNF} / \\
\text { Chitosan/CNT }\end{array}$ & [121] \\
\hline Congo red & $\begin{array}{c}\mathrm{Fe}_{3} \mathrm{O}_{4} / \mathrm{TiO}_{2} @ \mathrm{CNF} / \\
\text { Chitosan/CNT }\end{array}$ & [121] & $\begin{array}{l}\text { Ciprofloxacin } \\
\text { Ofloxacin }\end{array}$ & $\mathrm{CoS}_{2}-\mathrm{CuS@CNFs}$ & [125] \\
\hline RB5 & $\mathrm{NiFe}_{2} \mathrm{O}_{4} @ \mathrm{CNFs}$ & [124] & PMS & $\begin{array}{c}\text { CNFs- } \\
\mathrm{CoFe}_{2} \mathrm{O}_{4} / \mathrm{PVDF}\end{array}$ & [126] \\
\hline RhB & $\begin{array}{c}\text { BiOBr@CNFs } \\
\mathrm{Ag} / \mathrm{CN} @ \mathrm{CNFs}\end{array}$ & $\begin{array}{l}{[122]} \\
{[123]}\end{array}$ & & & \\
\hline
\end{tabular}

\subsubsection{Synthetic Applications of CNFs Grafted with Inorganic Catalysts}

The role of inorganic-functionalized CNFs in organic synthesis has been greatly extended in the last years, allowing notable development in the synthesis of compounds of high industrial interest. The main applications reported in literature are summarized in Figure 6.
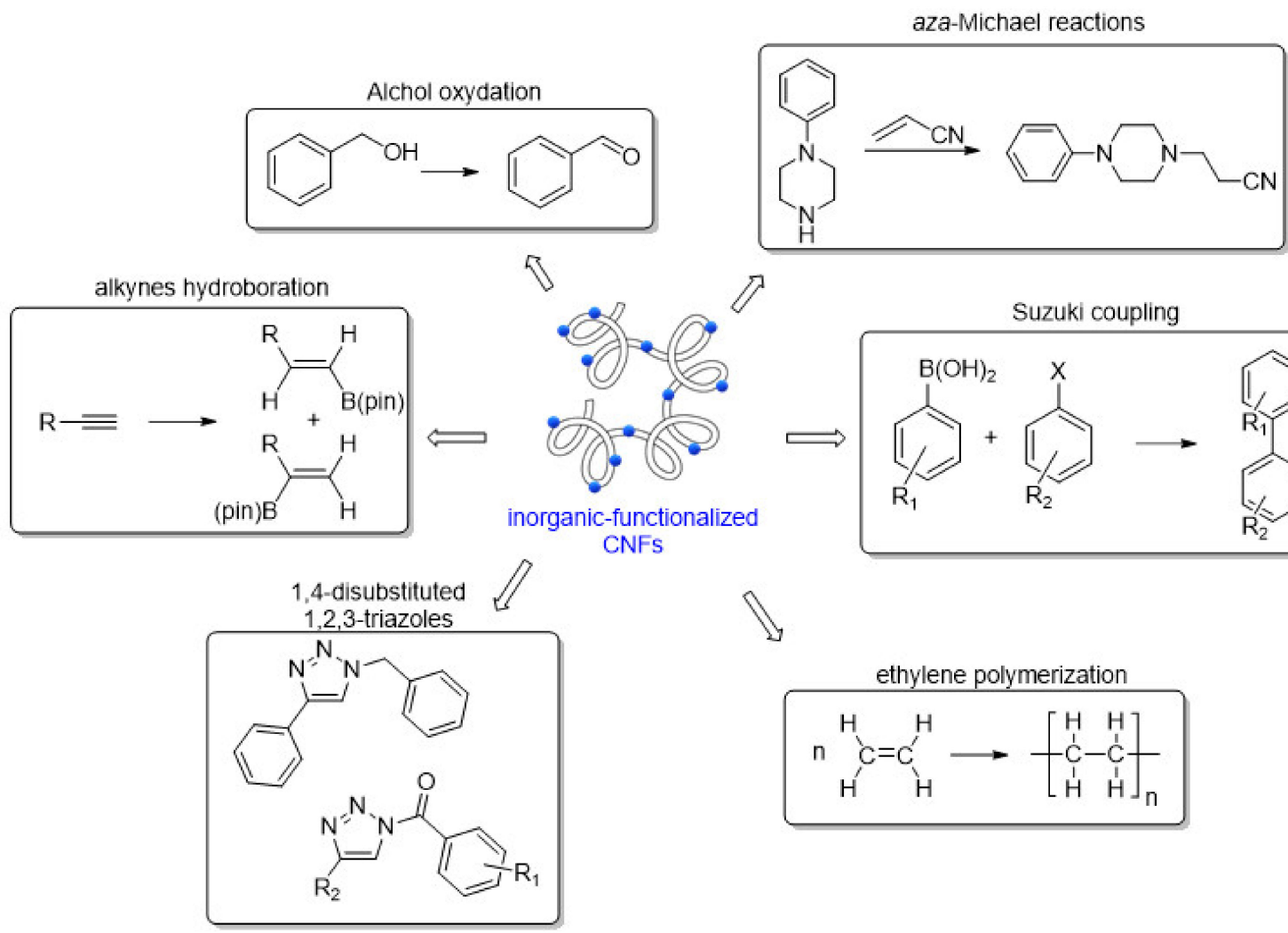

Figure 6. Catalytic applications of inorganic functionalized CNFs.

Hydroboration of alkynes 98a-98i using CNFs as template for inorganic catalysts was recently proposed by Zhang et al. [127]. In their work, functionalized CNFs were firstly 
functionalized via hydrolytic silane condensation in order to obtain their thiolated-form and, subsequently, employed as template for the immobilization of $\mathrm{Cu}(\mathrm{I})$ cations. As result, the CNFs-based nanosponges obtained showed high porosity and low density. The material was successfully tested as heterogenous catalyst, giving alkenes 99a-99i in excellent yields and up to $99 \%$ of regioselectivity. Furthermore, the reusability of the material was tested guaranteeing optimal catalytic performances until six reaction cycles. The reaction partners involved are reported in Table 13.

Table 13. Hydroboration of alkynes 98a-98i using a Cu@CNFs heterogeneous catalyst.

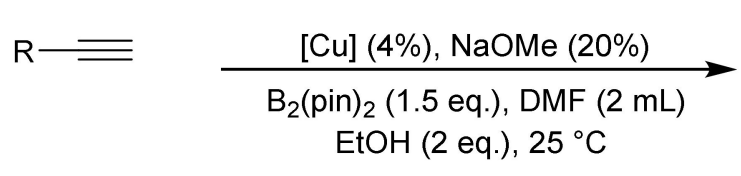

98a-98i

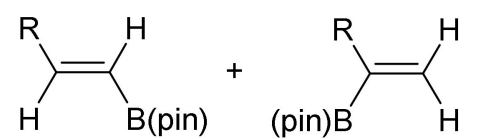

$99 a-99 i$

Entry

As for alcohol oxidation, an interesting example was presented by Gopiraman and co-workers in 2015 [128]. In this case, they were able to employ acetate-derivatives of CNFs in order to obtain anionic cellulose nanofibers (CNFs) acting as template for noble metal particles adsorption. The metals at the center of this work were $\mathrm{Ru}$ and Ag. The catalytic evaluation of the Ru-containing composite was tested on the aerobic conversion of benzyl alcohol to benzaldehyde, furnishing yields up to $89 \%$ and with $100 \%$ of selectivity. For the Ag-based composite, the model reaction was the $a z a$-Michael coupling between 100 and 101 giving yields of $99 \%$ and $100 \%$ selectivity. The catalytic cycle proposed for this reaction is illustrated in Scheme 15.

CNF derivatives as heterogeneous catalyst were also tested in Suzuki couplings, as reported by Jebali and collaborators [129]. In this regard, CNFs were employed in their cationic form in order to maximize the adsorption of $\mathrm{Pd} \mathrm{NPs} \mathrm{via} \mathrm{in} \mathrm{situ} \mathrm{reduction} \mathrm{of} \mathrm{PdCl}_{2}$. This simple approach gave a Pd-containing nanocomposite which was tested as catalyst on the coupling between aryl halides 102a-102g and arylboronic acid 10a. The results, listed in Table 14, report an almost quantitative reaction yield; in addition, several reusability tests were successfully performed obtaining the above reported performances up to three catalytic cycles. 


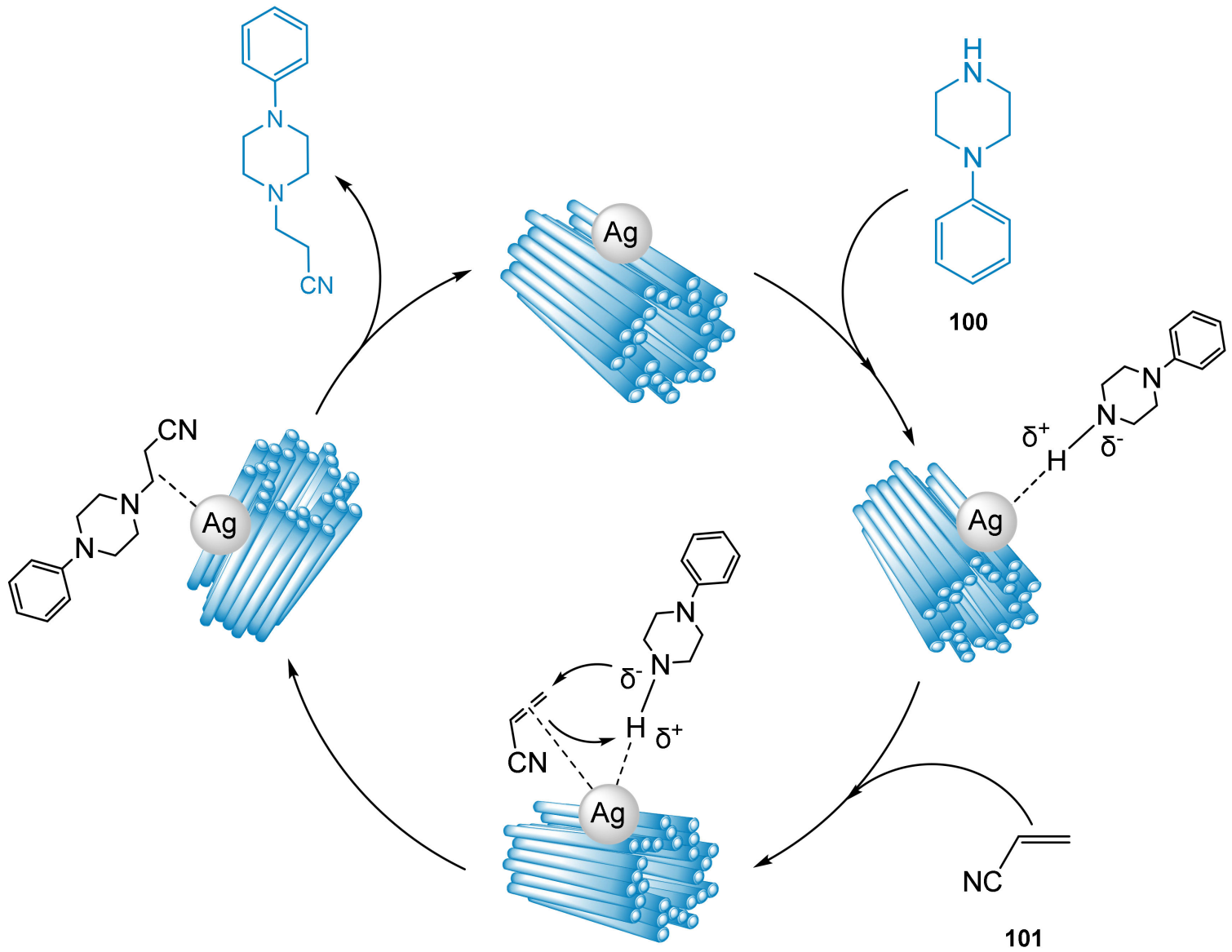

Scheme 15. Catalytic cycle proposed by Gopiraman and co-workers for the CNFs@Ag NPs-catalyzed aza-Michael coupling of 1-phenylpiperazine $\mathbf{1 0 0}$ and acrylonitrile $\mathbf{1 0 1 .}$

Table 14. Suzuki coupling using Pd@CNF catalyst.

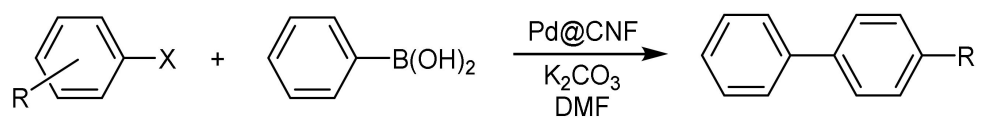

\begin{tabular}{cccccc}
\hline Entry & ArX & Conv. (\%) & Entry & ArX & Conv. (\%) \\
\hline 1 & 98 & 2 & & \\
\hline
\end{tabular}

A notable application of aerogel CNFs as catalytic templates was reported by Hees et al. in 2017 [130]. In this case, nanocellulose aerogels were obtained freeze-drying CNFs and subsequently impregnated with methylaluminoxane. This organic layer worked as support for the immobilization of bisiminopyridine iron(II) complexes, which served as catalyst for the low-pressure polymerization of ethylene.

Last, but not least, two important catalytic applications of inorganic-functionalized CNFs were proposed by Koga [131] and Ghamari Kargar and respective collaborators [132]. In the first case, the catalyst was prepared from $\mathrm{CNF}$ decorated with $\mathrm{Cu}(\mathrm{I})$. The latter was 
employed with respect to the Huisgen [3+2] cycloaddition reaction involving benzylazide 104 and phenylacetylene 105 obtaining 1,2,3-triazoles 1,4-disubstituted in high yields (Figure 7).

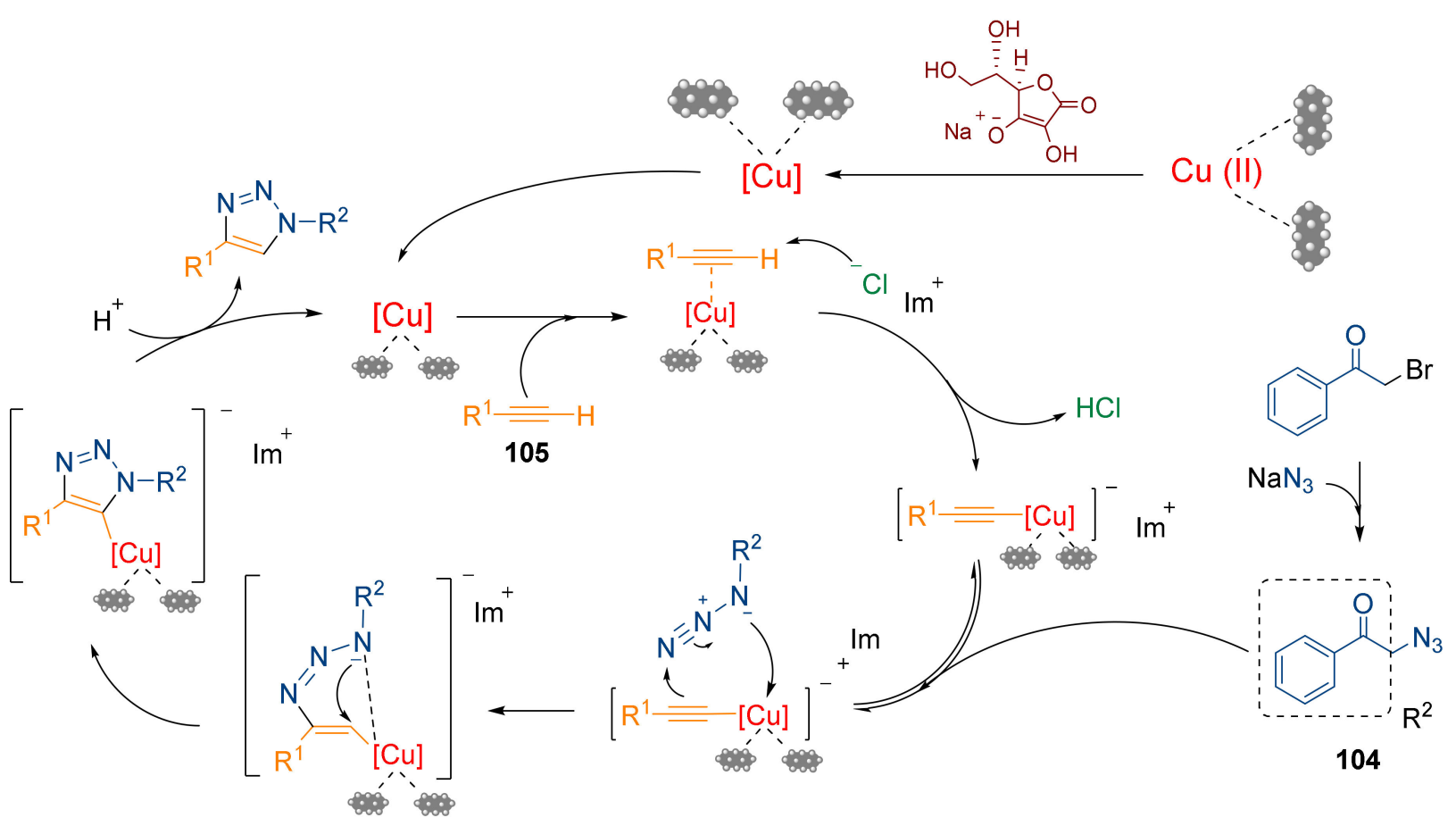

Figure 7. $\mathrm{Fe}_{3} \mathrm{O}_{4} @ \mathrm{CNF}-\mathrm{ImSalophCu}$-catalyzed mechanism for 1,4-disubstituted 1,2,3-triazoles synthesis.

In the second case, the research group of Ghamari Kargar proposed a new approach for the synthesis of 1,2,3-triazole derivatives employing the $\mathrm{Fe}_{3} \mathrm{O}_{4} @ \mathrm{CNF}-\mathrm{ImSalophCu}$ nanocatalyst illustrated in Figure 8. Particularly, it was realized the one-pot three component reaction between phenacyl bromides, sodium azide and alkynes, obtaining 1,4-disubstituted 1,2,3-triazoles in yields up to $98 \%$.

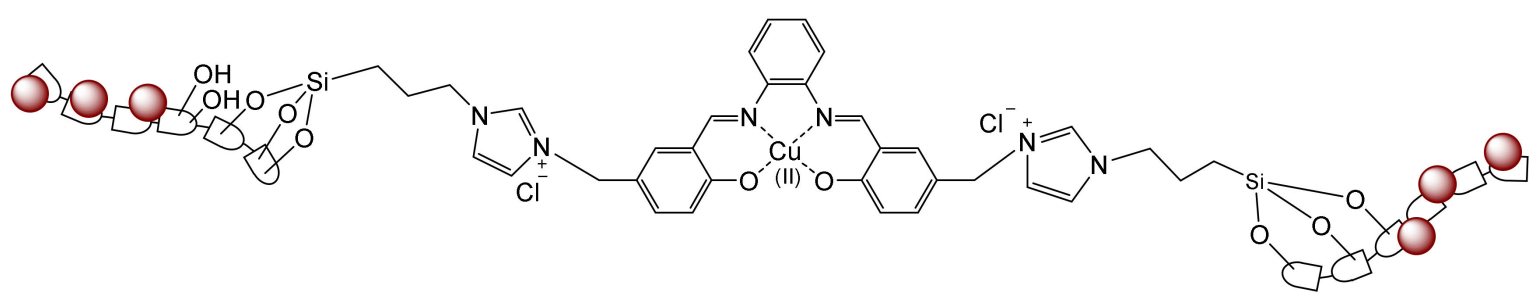

Figure 8. $\mathrm{Fe}_{3} \mathrm{O}_{4} @ \mathrm{CNF}-\mathrm{ImSalophCu}$ nanocomposite.

\subsection{Organic-Functionalized CNF Employed in Catalysis}

The use of CNFs derivatives enriched with organic moieties for catalytic applications have recently seen interesting developments in diverse fields of organic synthesis. In 2018, two important applications were proposed. In the first example, TEMPO-oxidized CNFs (TOCNs) were successfully applied as organocatalysts in hydrolysis of acetals $\mathbf{1 0 6}$ to aldehydes 107 [133] (Scheme 16) with very good performances and quantitative yields. 
<smiles>[R][R]C(O[R1])c1ccc([R])cc1</smiles>

106 $\underset{\text { dioxane }}{\stackrel{\text { TOCN, } \mathrm{H}_{2} \mathrm{O}(\mathrm{pH} 4)}{\longrightarrow}}$ room temperature (r.t.)

$2 \mathrm{~h}$<smiles>[R][X]c1ccc(C=O)cc1</smiles>

107

Scheme 16. TOCN-catalyzed hydrolysis of acetals 106.

In the second application, an organocatalytic system based on TOCN and (S)-proline (TOCN-(S)-proline) was realized and successfully applied to the coupling of 4-nitrobenzaldehyde $\mathbf{1 0 8}$ and acetone $\mathbf{1 0 9}$ to $\mathbf{1 1 0}$ (Scheme 17) [134].

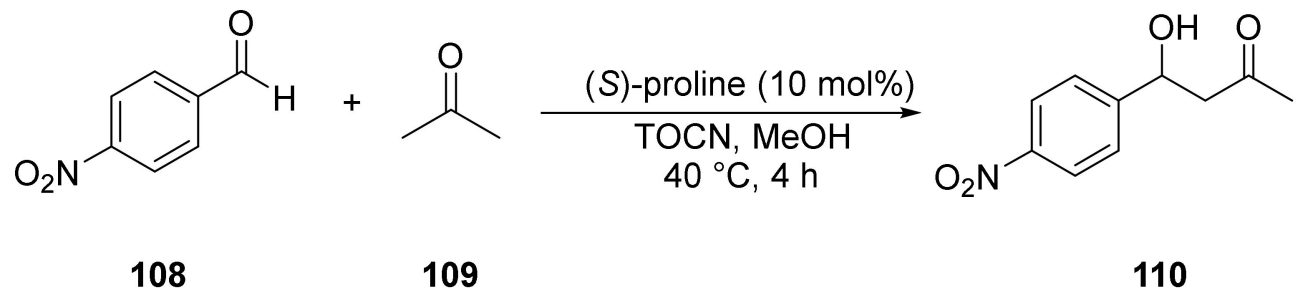

Scheme 17. TOCN-(S)-proline in direct aldol reaction between 4-nitrobenzaldehyde $\mathbf{1 0 8}$ and acetone 109.

In this case, the so-realized reaction gave yields up to $99 \%$ with an enantiomeric excess (ee) in the syn form of $89 \%$ of the compound 110 . The employ of the sole TOCNs without (S)-proline gave a very low yield (18\%) and a poorer selectivity (64\% ee), confirming the importance of the (S)-proline in the catalytic system. The potential of this kind of catalytic system have been also extended to the Michael addition of ketones to $\omega$-nitrostyrene resulting in good yields and syn:anti selectivity [135].

Furthermore, amine-functionalized TOCNs have been proved to be efficient as cooperative acid-base organocatalysts [136]. In this work, TOCNs were cross-linked with polyethylenimine (PEI) forming a hydrogel (TOCNF-PEI) employed to catalyze the in batch and flow condensation of 4-NBA and acetone.

In 2020, organic-decorated CNFs derivatives were also employed to the ring opening polymerization of lactide [137] and the synthesis of tetraketones in aqueous medium [138]. In the first case, the surface-initiated ring opening polymerization (SI-ROP) with rac-lactide 112 was realized using $\mathrm{N}, \mathrm{N}$-dimethyl aminopyridine (DMAP) in dichloromethane (DCM) (Scheme 18).

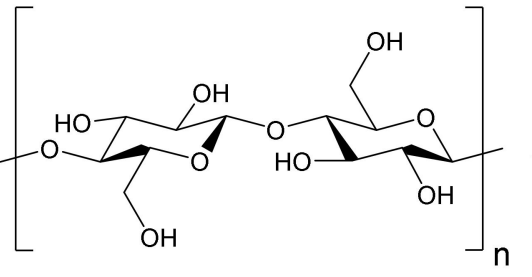

111<smiles>CC1OC(=O)C(C)OC1=O</smiles>

112
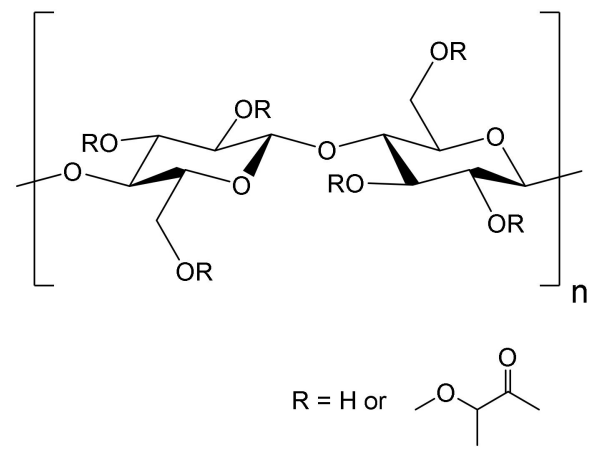

113

Scheme 18. Reaction scheme of SI-ROP with rac-lactide using DMAP reported by Lalanne-Tisné and co-workers.

In addition, the functionalization of cellulose nanofibers with 1,8-diazabicyclo [5.4.0] undec-7-ene (DBU) furnished a catalyst able to catalyze the coupling of aldehydes and 
diketones in water at room temperature. This approach enabled yields up to $96 \%$ and to be achieved interesting reusability properties.

\section{Conclusions}

NCs represent an important contributor to chemical synthesis in terms of eco-sustainability and efficiency. In this regard, this review fills the lack of totally focused overview on inorganic and organic-decorated NCs as heterogeneous catalysts. In particular, BNC and CNFs are shown to possess promising properties in terms of both inorganic and organicmediated catalysis, while CNCs reveal themselves to be a powerful tool as template for the grow of metallic NPs-catalysts, and in particular for the transformation of chemicals for environmental purposes. Nonetheless, it is conceivable that there is a synergistic contribution between the functional portion of the catalyst (NPs, organic framework, etc.) and its polysaccharidic backbone, making the entire nanomaterial a "non-innocent" template. These aspects, united with the numerous examples in terms of easy disposability, reusability, cheapness, and high chemical tunability of the catalysts reported above, increasingly enhance the central role assumed by NCs in chemistry.

Author Contributions: Conceptualization, A.D.N., L.M., V.A., F.O., and M.A.T.; methodology, V.A., F.O., M.A.T., and P.C.; data curation, V.A., F.O., M.A.T., A.J., and P.C.; writing-original draft preparation, A.D.N., V.A., F.O., M.A.T., A.J., and P.C.; writing-review and editing, A.D.N. and L.M.; supervision, A.D.N. and L.M. All authors have read and agreed to the published version of the manuscript.

Funding: This research received no external funding.

Institutional Review Board Statement: Not applicable.

Informed Consent Statement: Not applicable.

Data Availability Statement: Date is contained within the article.

Acknowledgments: We thank the Italian Ministry of University and Research (MUR) for a doctoral grant and the University of Calabria for financial support.

Conflicts of Interest: The authors declare no conflict of interest.

\section{References}

1. French, A.D.; Pérez, S.; Bulone, V.; Rosenau, T.; Gray, D. Cellulose; John Wiley \& Sons: New York, NY, USA, 2018; Volume 1838, ISBN 0471440264.

2. Kirk, O. Kirk-Othmer Encyclopedia of Chemical Technology, 5th ed.; John Wiley \& Sons: New York, NY, USA, 2004.

3. Bellesia, G.; Asztalos, A.; Shen, T.; Langan, P.; Redondo, A.; Gnanakaran, S. In silico studies of crystalline cellulose and its degradation by enzymes. Acta Crystallogr. Sect. D Biol. Crystallogr. 2010, 66, 1184-1188. [CrossRef]

4. Isikgor, F.H.; Becer, C.R. Lignocellulosic biomass: A sustainable platform for the production of bio-based chemicals and polymers. Polym. Chem. 2015, 6, 4497-4559. [CrossRef]

5. Romeo, I.; Olivito, F.; Tursi, A.; Algieri, V.; Beneduci, A.; Chidichimo, G.; Maiuolo, L.; Sicilia, E.; De Nino, A. Totally green cellulose conversion into bio-oil and cellulose citrate using molten citric acid in an open system: Synthesis, characterization and computational investigation of reaction mechanisms. RSC Adv. 2020, 10, 34738-34751. [CrossRef]

6. Thomas, B.; Raj, M.C.; Athira, B.K.; Rubiyah, H.M.; Joy, J.; Moores, A.; Drisko, G.L.; Sanchez, C. Nanocellulose, a Versatile Green Platform: From Biosources to Materials and Their Applications. Chem. Rev. 2018, 118, 11575-11625. [CrossRef] [PubMed]

7. Klemm, D.; Cranston, E.D.; Fischer, D.; Gama, M.; Kedzior, S.A.; Kralisch, D.; Kramer, F.; Kondo, T.; Lindström, T.; Nietzsche, S.; et al. Nanocellulose as a natural source for groundbreaking applications in materials science: Today's state. Mater. Today 2018, 21, 720-748. [CrossRef]

8. Mariano, M.; El Kissi, N.; Dufresne, A. Cellulose nanocrystals and related nanocomposites: Review of some properties and challenges. J. Polym. Sci. Part B Polym. Phys. 2014, 52, 791-806. [CrossRef]

9. Zhang, Q.; Zhang, L.; Wu, W.; Xiao, H. Methods and applications of nanocellulose loaded with inorganic nanomaterials: A review. Carbohydr. Polym. 2020, 229, 115454. [CrossRef] [PubMed]

10. Kaushik, M.; Moores, A. Review: Nanocelluloses as versatile supports for metal nanoparticles and their applications in catalysis. Green Chem. 2016, 18, 622-637. [CrossRef]

11. Brown, A.J. On an acetic ferment which forms cellulose. J. Chem. Soc. Trans. 1886, 49, 432-439. [CrossRef] 
12. Foresti, M.L.; Vázquez, A.; Boury, B. Applications of bacterial cellulose as precursor of carbon and composites with metal oxide, metal sulfide and metal nanoparticles: A review of recent advances. Carbohydr. Polym. 2017, 157, 447-467. [CrossRef]

13. Qiu, K.; Netravali, A.N. A review of fabrication and applications of bacterial cellulose based nanocomposites. Polym. Rev. 2014, 54, 598-626. [CrossRef]

14. Soriano, M.L.; Dueñas-Mas, M.J. Promising Sensing Platforms Based on Nanocellulose. In Carbon-Based Nanosensor Technology; Springer Series on Chemical Sensors and Biosensors (Methods and Applications); Kranz, C., Ed.; Springer: Berlin/Heidelberg, Germany, 2018; pp. 273-301.

15. Hu, W.; Chen, S.; Yang, J.; Li, Z.; Wang, H. Functionalized bacterial cellulose derivatives and nanocomposites. Carbohydr. Polym. 2014, 101, 1043-1060. [CrossRef] [PubMed]

16. Torres, F.G.; Arroyo, J.J.; Troncoso, O.P. Bacterial cellulose nanocomposites: An all-nano type of material. Mater. Sci. Eng. C 2019, 98, 1277-1293. [CrossRef] [PubMed]

17. Andriani, D.; Apriyana, A.Y.; Karina, M. The optimization of bacterial cellulose production and its applications: A review. Cellulose 2020, 27, 6747-6766. [CrossRef]

18. Long, L.Y.; Weng, Y.X.; Wang, Y.Z. Cellulose aerogels: Synthesis, applications, and prospects. Polymers (Basel) 2018, 8, 623. [CrossRef] [PubMed]

19. Bonaccorsi, L.; Calandra, P.; Amenitsch, H.; Proverbio, E.; Lombardo, D. Growth of fractal aggregates during template directed SAPO-34 zeolite formation. Microporous Mesoporous Mater. 2013, 167, 3-9. [CrossRef]

20. Wu, Z.Y.; Liang, H.W.; Chen, L.F.; Hu, B.C.; Yu, S.H. Bacterial Cellulose: A Robust Platform for Design of Three Dimensional Carbon-Based Functional Nanomaterials. Acc. Chem. Res. 2016, 49, 96-105. [CrossRef]

21. Mohamed, M.A.; Abd Mutalib, M.; Mohd Hir, Z.A.; Zain, M.F.M.; Mohamad, A.B.; Jeffery Minggu, L.; Awang, N.A.; Salleh, W.N.W. An overview on cellulose-based material in tailoring bio-hybrid nanostructured photocatalysts for water treatment and renewable energy applications. Int. J. Biol. Macromol. 2017, 103, 1232-1256. [CrossRef]

22. Li, Y.Y.; Wang, B.; Ma, M.G.; Wang, B. Review of Recent Development on Preparation, Properties, and Applications of CelluloseBased Functional Materials. Int. J. Polym. Sci. 2018, 2018. [CrossRef]

23. Ludwicka, K.; Kaczmarek, M.; Białkowska, A. Bacterial nanocellulose-a biobased polymer for active and intelligent food packaging applications: Recent advances and developments. Polymers (Basel) 2020, 12, 2209. [CrossRef]

24. Nasrollahzadeh, M.; Sajjadi, M.; Iravani, S.; Varma, R.S. Starch, cellulose, pectin, gum, alginate, chitin and chitosan derived (nano)materials for sustainable water treatment: A review. Carbohydr. Polym. 2021, 251, 116986. [CrossRef] [PubMed]

25. Jiang, Y.; Lawan, I.; Zhou, W.; Zhang, M.; Fernando, G.F.; Wang, L.; Yuan, Z. Synthesis, properties and photocatalytic activity of a semiconductor/cellulose composite for dye degradation-a review. Cellulose 2020, 27, 595-609. [CrossRef]

26. Sharma, C.; Bhardwaj, N.K. Bacterial nanocellulose: Present status, biomedical applications and future perspectives. Mater. Sci. Eng. C 2019, 104, 109963. [CrossRef] [PubMed]

27. Thiruvengadam, V.; Vitta, S. Bacterial cellulose based flexible multifunctional nanocomposite sheets. Cellulose 2017, 24, 3341-3351. [CrossRef]

28. Xu, T.; Jiang, Q.; Ghim, D.; Liu, K.K.; Sun, H.; Derami, H.G.; Wang, Z.; Tadepalli, S.; Jun, Y.S.; Zhang, Q.; et al. Catalytically Active Bacterial Nanocellulose-Based Ultrafiltration Membrane. Small 2018, 14, 1-8. [CrossRef]

29. Kamal, T.; Ahmad, I.; Khan, S.B.; Asiri, A.M. Bacterial cellulose as support for biopolymer stabilized catalytic cobalt nanoparticles. Int. J. Biol. Macromol. 2019, 135, 1162-1170. [CrossRef]

30. Kamal, T.; Ahmad, I.; Khan, S.B.; Ul-Islam, M.; Asiri, A.M. Microwave Assisted Synthesis and Carboxymethyl Cellulose Stabilized Copper Nanoparticles on Bacterial Cellulose Nanofibers Support for Pollutants Degradation. J. Polym. Environ. 2019, 27, $2867-2877$. [CrossRef]

31. Kamal, T.; Ahmad, I.; Khan, S.B.; Asiri, A.M. Anionic polysaccharide stabilized nickel nanoparticles-coated bacterial cellulose as a highly efficient dip-catalyst for pollutants reduction. React. Funct. Polym. 2019, 145, 104395. [CrossRef]

32. Chen, Y.; Chen, S.; Wang, B.; Yao, J.; Wang, H. TEMPO-oxidized bacterial cellulose nanofibers-supported gold nanoparticles with superior catalytic properties. Carbohydr. Polym. 2017, 160, 34-42. [CrossRef]

33. Sen, I.K.; Maity, K.; Islam, S.S. Green synthesis of gold nanoparticles using a glucan of an edible mushroom and study of catalytic activity. Carbohydr. Polym. 2013, 91, 518-528. [CrossRef]

34. Wibowo, A.; Indrawan, R.F.; Triadhi, U.; Aimon, H.A.; Iskandar, F.; Ardy, H. Simple preparation of Fenton catalyst@bacterial cellulose for waste water treatment. Mater. Res. Express 2018, 5, 024005. [CrossRef]

35. Hu, J.; Wu, D.; Feng, Q.; Wei, A.; Song, B. Soft High-Loading TiO2 Composite Biomaterial Film as an Efficient and Recyclable Catalyst for Removing Methylene Blue. Fibers Polym. 2020, 21, 1760-1766. [CrossRef]

36. Zhou, Y.; Guo, X.; Li, X.; Fu, J.; Liu, J.; Hong, F.; Qiao, J. In-situ growth of CuO/Cu nanocomposite electrode for efficient CO2 electroreduction to $\mathrm{CO}$ with bacterial cellulose as support. J. $\mathrm{CO}_{2}$ Util. 2020, 37, 188-194. [CrossRef]

37. Jeremic, S.; Djokic, L.; Ajdačić, V.; Božinović, N.; Pavlovic, V.; Manojlović, D.D.; Babu, R.; Senthamaraikannan, R.; Rojas, O.; Opsenica, I.; et al. Production of bacterial nanocellulose (BNC) and its application as a solid support in transition metal catalysed cross-coupling reactions. Int. J. Biol. Macromol. 2019, 129, 351-360. [CrossRef] [PubMed]

38. Davis, R.; Kataria, R.; Cerrone, F.; Woods, T.; Kenny, S.; O’Donovan, A.; Guzik, M.; Shaikh, H.; Duane, G.; Gupta, V.K.; et al. Conversion of grass biomass into fermentable sugars and its utilization for medium chain length polyhydroxyalkanoate (mclPHA) production by Pseudomonas strains. Bioresour. Technol. 2013, 150, 202-209. [CrossRef] [PubMed] 
39. Nikoofar, K.; Heidari, H.; Shahedi, Y. Investigation the catalytic activity of nanofibrillated and nanobacterial cellulose sulfuric acid in synthesis of dihydropyrimidoquinolinetriones. Res. Chem. Intermed. 2018, 44, 4533-4546. [CrossRef]

40. Costanzo, P.; Nardi, M.; Oliverio, M. Similarity and Competition between Biginelli and Hantzsch Reactions: An Opportunity for Modern Medicinal Chemistry. Eur. J. Org. Chem. 2020, 2020, 3954-3964. [CrossRef]

41. Oliverio, M.; Costanzo, P.; Nardi, M.; Rivalta, I.; Procopio, A. Facile ecofriendly synthesis of monastrol and its structural isomers via biginelli reaction. ACS Sustain. Chem. Eng. 2014, 2, 1228-1233. [CrossRef]

42. Costanzo, P.; Calandruccio, C.; Di Gioia, M.L.; Nardi, M.; Oliverio, M.; Procopio, A. First multicomponent reaction exploiting glycerol carbonate synthesis. J. Clean. Prod. 2018, 202, 504-509. [CrossRef]

43. Choudhury, P.; Ghosh, P.; Basu, B. Amine-functionalized graphene oxide nanosheets (AFGONs): An efficient bifunctional catalyst for selective formation of 1,4-dihydropyridines, acridinediones and polyhydroquinolines. Mol. Divers. 2020, 24, 283-294. [CrossRef]

44. Said, M.S.; Khonde, N.S.; Thorat, M.N.; Atapalkar, R.S.; Kulkarni, A.A.; Gajbhiye, J.; Dastager, S.G. A New TBAF Complex, Highly Stable, Facile and Selective Source for Nucleophilic Fluorination: Applications in Batch and Flow Chemistry. Asian J. Org. Chem. 2020, 9, 1022-1026. [CrossRef]

45. Haldar, D.; Purkait, M.K. Micro and nanocrystalline cellulose derivatives of lignocellulosic biomass: A review on synthesis, applications and advancements. Carbohydr. Polym. 2020, 250, 116937. [CrossRef] [PubMed]

46. Carneiro de Oliveira, J.; Rigolet, S.; Marichal, C.; Roucoules, V.; Laborie, M.P. Grafting Diels-Alder moieties on cellulose nanocrystals through carbamation. Carbohydr. Polym. 2020, 250, 116966. [CrossRef] [PubMed]

47. Kovacs, T.; Naish, V.; O'Connor, B.; Blaise, C.; Gagné, F.; Hall, L.; Trudeau, V.; Martel, P. An ecotoxicological characterization of nanocrystalline cellulose (NCC). Nanotoxicology 2010, 4, 255-270. [CrossRef] [PubMed]

48. Lu, P.; Hsieh, Y. Lo Preparation and properties of cellulose nanocrystals: Rods, spheres, and network. Carbohydr. Polym. 2010, 82, 329-336. [CrossRef]

49. Feng, K.; Gao, X.; Gu, Z.; Jin, Z. Improving Homogeneity of Iridescent Cellulose Nanocrystal Films by Surfactant-Assisted Spreading Self-Assembly. ACS Sustain. Chem. Eng. 2019, 7, 19062-19071. [CrossRef]

50. Mendoza-Galván, A.; Tejeda-Galán, T.; Domínguez-Gómez, A.B.; Mauricio-Sánchez, R.A.; Järrendahl, K.; Arwin, H. Linear birefringent films of cellulose nanocrystals produced by dip-coating. Nanomaterials 2019, 9, 45. [CrossRef]

51. Ali, S.D.; Imiete, I.E.; Orlandi, M.E.; Castellani, L.; Hanel, T.; Zoia, L. Novel CNC/silica hybrid as potential reinforcing filler for natural rubber compounds. J. Appl. Polym. Sci. 2020, 137, 1-11. [CrossRef]

52. Wang, P.X.; Hamad, W.Y.; MacLachlan, M.J. Polymer and Mesoporous Silica Microspheres with Chiral Nematic Order from Cellulose Nanocrystals. Angew. Chem. Int. Ed. 2016, 55, 12460-12464. [CrossRef]

53. Talantikite, M.; Beury, N.; Moreau, C.; Cathala, B. Arabinoxylan/Cellulose Nanocrystal Hydrogels with Tunable Mechanical Properties. Langmuir 2019, 35, 13427-13434. [CrossRef]

54. Zhang, Y.; Yin, M.; Li, L.; Fan, B.; Liu, Y.; Li, R.; Ren, X.; Huang, T.S.; Kim, I.S. Construction of aerogels based on nanocrystalline cellulose and chitosan for high efficient oil/water separation and water disinfection. Carbohydr. Polym. 2020, $243,116461$. [CrossRef] [PubMed]

55. Jiang, X.; Lou, C.; Hua, F.; Deng, H.; Tian, X. Cellulose nanocrystals-based flocculants for high-speed and high-efficiency decolorization of colored effluents. J. Clean. Prod. 2020, 251. [CrossRef]

56. Wang, S.; Dong, L.; Li, Z.; Lin, N.; Xu, H.; Gao, S. Sustainable supercapacitors of nitrogen-doping porous carbon based on cellulose nanocrystals and urea. Int. J. Biol. Macromol. 2020, 164, 4095-4103. [CrossRef] [PubMed]

57. Kaushik, M.; Friedman, H.M.; Bateman, M.; Moores, A. Cellulose nanocrystals as non-innocent supports for the synthesis of ruthenium nanoparticles and their application to arene hydrogenation. RSC Adv. 2015, 5, 53207-53210. [CrossRef]

58. Moodley, V.; Maddila, S.; Jonnalagadda, S.B.; Van Zyl, W.E. Synthesis of triazolidine-3-one derivatives through the nanocellulose/hydroxyapatite-catalyzed reaction of aldehydes and semicarbazide. New J. Chem. 2017, 41, 6455-6463. [CrossRef]

59. Helmiyati; Anggraini, Y. Nanocomposites comprising cellulose and nanomagnetite as heterogeneous catalysts for the synthesis of biodiesel from oleic acid. Int. J. Technol. 2019, 10, 798-807. [CrossRef]

60. Mirosanloo, A.; Zareyee, D.; Khalilzadeh, M.A. Recyclable cellulose nanocrystal supported Palladium nanoparticles as an efficient heterogeneous catalyst for the solvent-free synthesis of coumarin derivatives via von Pechmann condensation. Appl. Organomet. Chem. 2018, 32, 1-9. [CrossRef]

61. Nikoofar, K.; Heidari, H.; Shahedi, Y. Nano crystalline cellulose sulfuric acid (s-NCC): A novel green nanocatalyst for the synthesis of polyhydroxy pyrimidine-fused heterocyclic compounds (PPFHs). Cellulose 2018, 25, 5697-5709. [CrossRef]

62. An, X.; Long, Y.; Ni, Y. Cellulose nanocrystal/hexadecyltrimethylammonium bromide/silver nanoparticle composite as a catalyst for reduction of 4-nitrophenol. Carbohydr. Polym. 2017, 156, 253-258. [CrossRef]

63. Turco Liveri, V.; Lombardo, D.; Pochylski, M.; Calandra, P. Molecular association of small amphiphiles: Origin of ionic liquid properties in dibutyl phosphate/propylamine binary mixtures. J. Mol. Liq. 2018, 263, 274-281. [CrossRef]

64. Calandra, P.; Ruggirello, A.; Mele, A.; Turco Liveri, V. Self-assembly in surfactant-based liquid mixtures: Bis(2-ethylhexyl)phosphoric acid/bis(2-ethylhexyl)amine systems. J. Colloid Interface Sci. 2010, 348, 183-188. [CrossRef] [PubMed]

65. Calandra, P.; Turco Liveri, V.; Riello, P.; Freris, I.; Mandanici, A. Self-assembly in surfactant-based liquid mixtures: Octanoic acid/Bis(2-ethylhexyl)amine systems. J. Colloid Interface Sci. 2012, 367, 280-285. [CrossRef] 
66. Calandra, P.; Nicotera, I.; Oliviero Rossi, C.; Turco Liveri, V. Dynamical properties of self-assembled surfactant-based mixtures: Triggering of one-dimensional anomalous diffusion in Bis(2-ethylhexyl)phosphoric acid/ $\mathrm{n}$-octylamine systems. Langmuir 2013, 29, 14848-14854. [CrossRef] [PubMed]

67. Calandra, P.; Ruggirello, A.; Pistone, A.; Turco Liveri, V. Structural and Optical Properties of Novel Surfactant Coated TiO2-Ag Based Nanoparticles. J. Clust. Sci. 2010, 21, 767-778. [CrossRef]

68. Zhang, S.; Zhao, D.; Hou, C.; Liang, C.; Li, H. Facile one-pot synthesis of cellulose nanocrystal-supported hollow CuFe2O4 nanoparticles as efficient catalyst for 4-nitrophenol reduction. J. Nanopart. Res. 2018, 20. [CrossRef]

69. Zhan, Y.; Meng, Y.; Li, W.; Chen, Z.; Yan, N.; Li, Y.; Teng, M. Magnetic recoverable MnFe2O4/cellulose nanocrystal composites as an efficient catalyst for decomposition of methylene blue. Ind. Crops Prod. 2018, 122, 422-429. [CrossRef]

70. Dhar, P.; Kumar, A.; Katiyar, V. Fabrication of cellulose nanocrystal supported stable Fe(0) nanoparticles: A sustainable catalyst for dye reduction, organic conversion and chemo-magnetic propulsion. Cellulose 2015, 22, 3755-3771. [CrossRef]

71. Goswami, M.; Das, A.M. Synthesis of cellulose impregnated copper nanoparticles as an efficient heterogeneous catalyst for C-N coupling reactions under mild conditions. Carbohydr. Polym. 2018, 195, 189-198. [CrossRef]

72. Chetia, M.; Ali, A.A.; Bordoloi, A.; Sarma, D. Facile route for the regioselective synthesis of 1,4-disubstituted 1,2,3-triazole using copper nanoparticles supported on nanocellulose as recyclable heterogeneous catalyst. J. Chem. Sci. 2017, 129, 1211-1217. [CrossRef]

73. Maiuolo, L.; Algieri, V.; Olivito, F.; De Nino, A. Recent developments on 1,3-dipolar cycloaddition reactions by catalysis in green solvents. Catalysts 2020, 10, 65. [CrossRef]

74. De Nino, A.; Algieri, V.; Tallarida, M.A.; Constanzo, P.; Pedrón, M.; Tejero, T.; Merino, P.; Maiuolo, L. Regioselective Synthesis of 1,4,5-Trisubstituted-1,2,3-Triazoles from Aryl Azides and Enaminones. Eur. J. Org. Chem. 2019, 2019, 5725-5731. [CrossRef]

75. Maiuolo, L.; Russo, B.; Algieri, V.; Nardi, M.; Di Gioia, M.L.; Tallarida, M.A.; De Nino, A. Regioselective synthesis of 1,5disubstituted 1,2,3-triazoles by 1,3-dipolar cycloaddition: Role of $\operatorname{Er}(\mathrm{OTf}) 3$, ionic liquid and water. Tetrahedron Lett. 2019, 60, 672-674. [CrossRef]

76. De Nino, A.; Merino, P.; Algieri, V.; Nardi, M.; Di Gioia, M.L.; Russo, B.; Tallarida, M.A.; Maiuolo, L. Synthesis of 1,5-functionalized 1,2,3-triazoles using ionic liquid/iron(III) chloride as an efficient and reusable homogeneous catalyst. Catalysts 2018, 8, 364. [CrossRef]

77. Bozorov, K.; Zhao, J.; Aisa, H.A. 1,2,3-Triazole-containing hybrids as leads in medicinal chemistry: A recent overview. Bioorg. Med. Chem. 2019, 27, 3511-3531. [CrossRef]

78. Xu, Z.; Zhao, S.J.; Liu, Y. 1,2,3-Triazole-containing hybrids as potential anticancer agents: Current developments, action mechanisms and structure-activity relationships. Eur. J. Med. Chem. 2019, 183, 111700. [CrossRef]

79. Algieri, V.; Algieri, C.; Maiuolo, L.; De Nino, A.; Pagliarani, A.; Tallarida, M.A.; Trombetti, F.; Nesci, S. 1,5-Disubstituted-1,2,3triazoles as inhibitors of the mitochondrial Ca2+-activated F1FO-ATP(hydrol)ase and the permeability transition pore. Ann. N. Y. Acad. Sci. 2020, 1-13. [CrossRef]

80. Maiuolo, L.; De Nino, A.; Algieri, V.; Nardi, M. Microwave-Assisted 1,3-Dipolar Cyclo-addition: Recent Advances In Synthesis of Isoxazolidines. Mini. Rev. Org. Chem. 2017, 14, 136-142. [CrossRef]

81. Maiuolo, L.; Algieri, V.; Russo, B.; Tallarida, M.A.; Nardi, M.; Di Gioia, M.L.; Merchant, Z.; Merino, P.; Delso, I.; Nino, A. De Synthesis, biological and in silico evaluation of pure nucleobase-containing spiro (Indane-Isoxazolidine) derivatives as potential inhibitors of MDM2-p53 interaction. Molecules 2019, 24, 2909. [CrossRef]

82. Maiuolo, L.; Feriotto, G.; Algieri, V.; Nardi, M.; Russo, B.; Di Gioia, M.L.; Furia, E.; Tallarida, M.A.; Mischiati, C.; De Nino, A. Antiproliferative activity of novel isatinyl/indanyl nitrones (INs) as potential spin trapping agents of free radical intermediates. Medchemcomm 2018, 9, 299-304. [CrossRef]

83. Olivito, F.; Amodio, N.; Di Gioia, M.L.; Nardi, M.; Oliverio, M.; Juli, G.; Tassone, P.; Procopio, A. Synthesis and preliminary evaluation of the anti-cancer activity on A549 lung cancer cells of a series of unsaturated disulfides. Medchemcomm 2019, 10, 116-119. [CrossRef]

84. Olivito, F.; Costanzo, P.; Di Gioia, M.L.; Nardi, M.; Oliverio, M.; Procopio, A. Efficient synthesis of organic thioacetates in water. Org. Biomol. Chem. 2018, 16, 7753-7759. [CrossRef] [PubMed]

85. Dutta, A.; Chetia, M.; Ali, A.A.; Bordoloi, A.; Gehlot, P.S.; Kumar, A.; Sarma, D. Copper Nanoparticles Immobilized on Nanocellulose: A Novel and Efficient Heterogeneous Catalyst for Controlled and Selective Oxidation of Sulfides and Alcohols. Catal. Letters 2019, 149, 141-150. [CrossRef]

86. Paonessa, R.; Nardi, M.; Di Gioia, M.L.; Olivito, F.; Oliverio, M.; Procopio, A. Eco-friendly synthesis of lipophilic EGCG derivatives and antitumor and antioxidant evaluation. Nat. Prod. Commun. 2018, 13, 1117-1122. [CrossRef]

87. De Nino, A.; Tallarida, M.A.; Algieri, V.; Olivito, F.; Costanzo, P.; De Filpo, G.; Maiuolo, L. Sulfonated cellulose-based magnetic composite as useful media for water remediation from amine pollutants. Appl. Sci. 2020, 10, 8155. [CrossRef]

88. Mirjalili, B.B.F.; Imani, M. Fe3O4@NCs/BF0.2: A magnetic bio-based nanocatalyst for the synthesis of 2,3-dihydro-1H-perimidines. J. Chinese Chem. Soc. 2019, 66, 1542-1549. [CrossRef]

89. Liu, J.; Plog, A.; Groszewicz, P.; Zhao, L.; Xu, Y.; Breitzke, H.; Stark, A.; Hoffmann, R.; Gutmann, T.; Zhang, K.; et al. Design of a Heterogeneous Catalyst Based on Cellulose Nanocrystals for Cyclopropanation: Synthesis and Solid-State NMR Characterization. Chem. A Eur. J. 2015, 21, 12414-12420. [CrossRef] [PubMed] 
90. Turbak, A.F.; Snyder, F.W.; Sandberg, K.R. Microfibrillated cellulose, a new cellulose product: Properties, uses, and commercial potential. J. Appl. Polym. Sci. Appl. Polym. Symp. 1983, 37, 815-827.

91. Herrick, F.W.; Casebier, R.L.; Hamilton, J.K.; Sandberg, K.R. Microfibrillated cellulose: Morphology and accessibility. J. Appl. Polym. Sci. Appl. Polym. Symp. 1983, 37, 797-813.

92. Jonoobi, M.; Oladi, R.; Davoudpour, Y.; Oksman, K.; Dufresne, A.; Hamzeh, Y.; Davoodi, R. Different preparation methods and properties of nanostructured cellulose from various natural resources and residues: A review. Cellulose 2015, 22, 935-969. [CrossRef]

93. Kim, J.H.; Shim, B.S.; Kim, H.S.; Lee, Y.J.; Min, S.K.; Jang, D.; Abas, Z.; Kim, J. Review of nanocellulose for sustainable future materials. Int. J. Precis. Eng. Manuf. Green Technol. 2015, 2, 197-213. [CrossRef]

94. Nechyporchuk, O.; Belgacem, M.N.; Bras, J. Production of cellulose nanofibrils: A review of recent advances. Ind. Crops Prod. 2016, 93, 2-25. [CrossRef]

95. Pääkko, M.; Ankerfors, M.; Kosonen, H.; Nykänen, A.; Ahola, S.; Österberg, M.; Ruokolainen, J.; Laine, J.; Larsson, P.T.; Ikkala, O; et al. Enzymatic hydrolysis combined with mechanical shearing and high-pressure homogenization for nanoscale cellulose fibrils and strong gels. Biomacromolecules 2007, 8, 1934-1941. [CrossRef] [PubMed]

96. Henriksson, M.; Henriksson, G.; Berglund, L.A.; Lindström, T. An environmentally friendly method for enzyme-assisted preparation of microfibrillated cellulose (MFC) nanofibers. Eur. Polym. J. 2007, 43, 3434-3441. [CrossRef]

97. Isogai, A.; Saito, T.; Fukuzumi, H. TEMPO-oxidized cellulose nanofibers. Nanoscale 2011, 3, 71-85. [CrossRef] [PubMed]

98. Saito, T.; Kimura, S.; Nishiyama, Y.; Isogai, A. Cellulose nanofibers prepared by TEMPO-mediated oxidation of native cellulose. Biomacromolecules 2007, 8, 2485-2491. [CrossRef] [PubMed]

99. Wågberg, L.; Winter, L.; Ödberg, L.; Lindström, T. On the charge stoichiometry upon adsorption of a cationic polyelectrolyte on cellulosic materials. Colloids Surf. 1987, 27, 163-173. [CrossRef]

100. Moon, R.J.; Martini, A.; Nairn, J.; Simonsen, J.; Youngblood, J. Cellulose nanomaterials review: Structure, properties and nanocomposites. Chem. Soc. Rev. 2011, 40, 3941-3994. [CrossRef]

101. Klemm, D.; Kramer, F.; Moritz, S.; Lindström, T.; Ankerfors, M.; Gray, D.; Dorris, A. Nanocelluloses: A new family of nature-based materials. Angew. Chemie Int. Ed. 2011, 50, 5438-5466. [CrossRef]

102. Siró, I.; Plackett, D. Microfibrillated cellulose and new nanocomposite materials: A review. Cellulose 2010, 17, 459-494. [CrossRef]

103. Hyuk Jang, K.; Ok Kang, Y.; Ho Park, W. International Journal of Biological Macromolecules Functional cellulose-based nanofibers with catalytic activity: Effect of Ag content and Ag phase. Int. J. Biol. Macromol. 2014, 67, 394-400. [CrossRef]

104. Zhang, W.; Wang, X.; Zhang, Y.; Van Bochove, B.; Mäkilä, E. Robust shape-retaining nanocellulose-based aerogels decorated with silver nanoparticles for fast continuous catalytic discoloration of organic dyes. Sep. Purif. Technol. 2020, 242, 116523. [CrossRef]

105. Heidari, H. Ag Nanoparticle / Nanofibrillated Cellulose Composite as an Effective and Green Catalyst for Reduction of 4-Nitrophenol. J. Clust. Sci. 2018, 29, 475-481. [CrossRef]

106. Gopiraman, M.; Deng, D.; Saravanamoorthy, S.; Chung, I.; Kim, I.S. Gold, silver and nickel nanoparticle anchored cellulose nanofiber composites as highly active catalysts for the rapid and selective reduction of nitrophenols in water. RSC Adv. 2018, 8, 3014-3023. [CrossRef]

107. Gopiraman, M.; Saravanamoorthy, S. Green synthesis of Ag @ Au bimetallic regenerated cellulose nanofibers for catalytic applications †. New J. Chem. 2019, 43, 17090-17103. [CrossRef]

108. Cunha Arantes, A.C.; das Gracas Almeida, C.; Leite Dauzacker, L.C.; Bianchi, M.L.; Wood, D.F.; Williams, T.G.; Orts, W.J.; Denzin Tonoli, G.H. Renewable hybrid nanocatalyst from magnetite and cellulose for treatment of textile effluents. Carbohydr. Polym. 2017, 163, 101-107. [CrossRef]

109. Hou, C.; Chen, W.; Fu, L.; Zhang, S.; Liang, C.; Wang, Y. Facile synthesis of a Co/Fe bi-MOFs/CNF membrane nanocomposite and its application in the degradation of tetrabromobisphenol A. Carbohydr. Polym. 2020, 247, 116731. [CrossRef]

110. Gu, J.; Hu, C.; Zhang, W.; Dichiara, A.B. Applied Catalysis B: Environmental Reagentless preparation of shape memory cellulose nano fi bril aerogels decorated with Pd nanoparticles and their application in dye discoloration. Appl. Catal. B Environ. 2018, 237, 482-490. [CrossRef]

111. Ujihara, M.; Hsu, M.; Liou, J.; Imae, T. Journal of the Taiwan Institute of Chemical Engineers Hybridization of cellulose nanofiber with amine-polymers and its ability on sick house syndrome gas decomposition. J. Taiwan Inst. Chem. Eng. 2018, 92, 106-111. [CrossRef]

112. Esquivel-Pena, V.; Guccini, V.; Kumar, S.; Salazar-Alvarez, G.; Rodriguez de San Miguel, E.; de Gyves, J. Hybrids based on borate-functionalized cellulose nanofibers and noble-metal nanoparticles as sustainable catalysts for environmental applications. RSC Adv. 2020, 10, 12460-12468. [CrossRef]

113. Idrissi, N.E.L.; Mouden, A.E.L.; Kaddami, H. Novel biohybrid aerogel composites based on cellulosic and cobalt metallic nanoparticles: Efficient and recyclable catalysts for green reduction reactions Novel biohybrid aerogel composites based on cellulosic and cobalt metallic nanoparticles: Efficient. In Proceedings of the IOP Conference Series: Materials Science and Engineering, Marrakech, Morocco, 13-15 November 2019; 2020; p. 827.

114. Zhang, Y.; Zhou, K.; Zhang, L.; Wu, H.; Guo, J. Synthesis of mesoporous $\Gamma$-Al2O3 by using cellulose nanofiber as template for hydrodesulfurization of dibenzothiophene. Fuel 2019, 253, 431-440. [CrossRef]

115. Tian, C.; Liu, Z.; Wu, Y.; Lu, X.; Yang, T.; Tao, X.; Qing, Y. Natural-Cellulose-Nanofibril-Tailored NiFe Nanoparticles for Efficient Oxygen Evolution Reaction. ChemElectroChem 2019, 6, 3303-3310. [CrossRef] 
116. Tao, X.; Luo, S.; Tian, C.; Qing, Y.; Lu, X.; Yan, N.; Wu, Y. Ni@Ni2P Encapsulation in Interconnected N-Doped Carbonized Cellulose Nanofibril Network for Efficient Oxygen Evolution Reaction. ACS Sustain. Chem. Eng. 2020, 8, 1859-1867. [CrossRef]

117. Tian, C.; Yang, T.; Liu, Z.; Qing, Y.; Zhang, B.; Zhou, J.; Wu, Y. Well-aligned arrangement CoFe nanoparticles assisted with cellulose nanofibrils for efficient oxygen evolution reaction. Appl. Surf. Sci. 2020, 510, 145484. [CrossRef]

118. Lee, Y.R.; Yoo, H.; Choi, J.; Ahn, W.S. Electrocatalytic oxygen reduction over Co@Co3O4/N-doped porous carbon derived from pyrolysis of ZIF-8/67 on cellulose nanofibers. Cellulose 2020, 27, 2723-2735. [CrossRef]

119. Meng, H.; Liu, Y.; Liu, H.; Pei, S.; Yuan, X.; Li, H.; Zhang, Y. ZIF67@MFC-Derived Co/N-C@CNFs Interconnected Frameworks with Graphitic Carbon-Encapsulated Co Nanoparticles as Highly Stable and Efficient Electrocatalysts for Oxygen Reduction Reactions. ACS Appl. Mater. Interfaces 2020, 12, 41580-41589. [CrossRef] [PubMed]

120. Salama, A.; Mohamed, A.; Aboamera, N.M.; Osman, T.A.; Khattab, A. Photocatalytic degradation of organic dyes using composite nanofibers under UV irradiation. Appl. Nanosci. 2018, 8, 155-161. [CrossRef]

121. ZabihiSahebi, A.; Koushkbaghi, S.; Pishnamazi, M.; Askari, A.; Khosravi, R.; Irani, M. Synthesis of cellulose acetate/chitosan/ SWCNT/Fe3O4/TiO2 composite nanofibers for the removal of $\mathrm{Cr}(\mathrm{VI})$, As(V), Methylene blue and Congo red from aqueous solutions. Int. J. Biol. Macromol. 2019, 140, 1296-1304. [CrossRef]

122. Gan, L.; Geng, A.; Song, C.; Xu, L.; Wang, L.; Fang, X.; Han, S.; Cui, J.; Mei, C. Simultaneous removal of rhodamine B and Cr(VI) from water using cellulose carbon nanofiber incorporated with bismuth oxybromide: The effect of cellulose pyrolysis temperature on photocatalytic performance. Environ. Res. 2020, 185, 109414. [CrossRef]

123. Tian, C.; Tao, X.; Luo, S.; Qing, Y.; Lu, X.; She, J.; Wu, Y. Cellulose nanofibrils anchored Ag on graphitic carbon nitride for efficient photocatalysis under visible light. Environ. Sci. Nano 2018, 5, 2129-2143. [CrossRef]

124. Gupta, K.; Kaushik, A.; Tikoo, K.B.; Kumar, V.; Singhal, S. Enhanced catalytic activity of composites of NiFe2O4 and nano cellulose derived from waste biomass for the mitigation of organic pollutants. Arab. J. Chem. 2020, 13, 783-798. [CrossRef]

125. Zheng, Z.B.; Sun, J.J.; Fakhri, A.; Surendar, A.; Ibatova, A.Z.; Liu, J.B. Synthesis, photocatalytic, optical, electronic and biological properties of the CoS2-CuS on cellulose nanocomposites as novel nano catalyst by a sonochemical technology. J. Mater. Sci. Mater. Electron. 2018, 29, 18531-18539. [CrossRef]

126. Zhang, Y.; Chen, Q.; Liu, L.; Wang, Y.; Leung, M.K.H. Activation of peroxymonosulfate and recycled effluent filtration over cathode membrane CNFs-CoFe2O4/PVDF in a photocatalytic fuel cell for water pollution control. Chem. Eng. J. 2020, $399,125731$. [CrossRef]

127. Zhang, C.; Zhou, M.; Liu, S.; Wang, B.; Mao, Z.; Xu, H.; Zhong, Y.; Zhang, L.; Xu, B.; Sui, X. Copper-loaded nanocellulose sponge as a sustainable catalyst for regioselective hydroboration of alkynes. Carbohydr. Polym. 2018, 191, 17-24. [CrossRef]

128. Gopiraman, M.; Bang, H.; Yuan, G.; Yin, C.; Song, K.H.; Lee, J.S.; Chung, I.M.; Karvembu, R.; Kim, I.S. Noble metal/functionalized cellulose nanofiber composites for catalytic applications. Carbohydr. Polym. 2015, 132, 554-564. [CrossRef] [PubMed]

129. Jebali, Z.; Granados, A.; Nabili, A.; Boufi, S.; do Rego, A.M.B.; Majdoub, H.; Vallribera, A. Cationic cellulose nanofibrils as a green support of palladium nanoparticles: Catalyst evaluation in Suzuki reactions. Cellulose 2018, 25, 6963-6975. [CrossRef]

130. Hees, T.; Zhong, F.; Rudolph, T.; Walther, A.; Mülhaupt, R. Nanocellulose Aerogels for Supporting Iron Catalysts and In Situ Formation of Polyethylene Nanocomposites. Adv. Funct. Mater. 2017, 27, 1-8. [CrossRef]

131. Koga, H.; Azetsu, A.; Tokunaga, E.; Saito, T.; Isogai, A.; Kitaoka, T. Topological loading of $\mathrm{Cu}(\mathrm{I})$ catalysts onto crystalline cellulose nanofibrils for the Huisgen click reaction. J. Mater. Chem. 2012, 22, 5538-5542. [CrossRef]

132. Ghamari kargar, P.; Bagherzade, G.; Eshghi, H. Design and synthesis of magnetic Fe3O4@NFC-ImSalophCu nanocatalyst based on cellulose nanofibers as a new and highly efficient, reusable, stable and green catalyst for the synthesis of 1,2,3-triazoles. RSC Adv. 2020, 10, 32927-32937. [CrossRef]

133. Tamura, Y.; Kanomata, K.; Kitaoka, T. Interfacial Hydrolysis of Acetals on Protonated TEMPO-oxidized Cellulose Nanofibers. Sci. Rep. 2018, 8, 6-10. [CrossRef]

134. Kanomata, K.; Tatebayashi, N.; Habaki, X.; Kitaoka, T. Cooperative catalysis of cellulose nanofiber and organocatalyst in direct aldol reactions. Sci. Rep. 2018, 8, 6-10. [CrossRef]

135. Ranaivoarimanana, N.J.; Kanomata, K.; Kitaoka, T. Concerted catalysis by nanocellulose and proline in organocatalytic Michael additions. Molecules 2019, 24, 1231. [CrossRef] [PubMed]

136. Ellebracht, N.C.; Jones, C.W. Functionalized cellulose nanofibril aerogels as cooperative acid-base organocatalysts for liquid flow reactions. Carbohydr. Polym. 2020, 233, 115825. [CrossRef] [PubMed]

137. Lalanne-Tisné, M.; Mees, M.A.; Eyley, S.; Zinck, P.; Thielemans, W. Organocatalyzed ring opening polymerization of lactide from the surface of cellulose nanofibrils. Carbohydr. Polym. 2020, 250. [CrossRef] [PubMed]

138. Lasemi, Z.; Tajbakhsh, M.; Alinezhad, H.; Mehrparvar, F. 1,8-Diazabicyclo [5.4.0] undec-7-ene functionalized cellulose nanofibers as an efficient and reusable nanocatalyst for the synthesis of tetraketones in aqueous medium. Res. Chem. Intermed. 2020, 46, 3667-3682. [CrossRef] 